Nadezhda V. Pechishcheva' / Konstantin Yu. Shunyaev² / Olga V. Melchakova ${ }^{3}$

\title{
Zirconium in modern analytical chemistry
}

\author{
${ }^{1}$ Institute of Metallurgy, Ural Branch, Russian Academy of Sciences, Yekaterinburg, 620016 Russia, E-mail: \\ pechischeva@gmail.com \\ ${ }^{2}$ Ural Federal University named after the first President of Russia B. N. Yeltsin, ul. Mira 19, Yekaterinburg, 620002 Russia \\ ${ }^{3}$ Institute of Metallurgy, Ural Branch, Russian Academy of Sciences, ul. Amundsena 101, Yekaterinburg, 620016 Russia
}

\begin{abstract}
:
Detailed monographs on the analytical chemistry of zirconium, which is widely used in all fields of modern science and technology, were published in the 1960s-1970s of the last century. This review summarizes information on the modern methods for determination of zirconium in a great variety of natural, technical, and biological objects. Focus is made on the works published in scientific periodicals after 2005. Spectroscopic techniques of zirconium determination including molecular and atomic spectrometry, $\mathrm{X}$-ray fluorescence analysis, and electrochemical and activation methods are described. The paper also describes the applications of zirconium compounds, in particular, in analytical chemistry.
\end{abstract}

Keywords: electrochemical methods, spectrophotometry, spectroscopy, X-ray fluorescence analysis, zirconium DOI: 10.1515/revac-2017-0016

Received: August 14, 2017; Accepted: January 30, 2018

\section{Introduction: zirconium and its compounds in engineering, environment, and analytical chemistry}

The main purpose of the review is to summarize global experience in the determination of zirconium content in various objects over the past years.

Zirconium is a trace element; however, in the form of chemical compounds, it is widely distributed all over the world. Its content in the Earth's crust amounts to about $2 \cdot 10^{-2}$ wt.\% (Emsley 1991); it exceeds the content of nickel, copper, and zinc. Zirconium and its compounds have unique physicochemical properties that account for their application in engineering and science. Extreme corrosion resistance to many common acids and alkalis has promoted the application of this metal in chemical engineering. Zirconium makes copper, aluminum, and titanium alloys stronger and more heat and corrosion resistant (Han et al., 2014; Kumar, Muthaiah \& Mula, 2017; Samuel et al., 2015; Zhang et al., 2017a). The heat resistance of zirconium oxide is widely known; this compound is used as a refractory material in glass and ceramics industry and for the production of laboratory crucibles and lining of metallurgical furnaces (ASTM C545-97, 2013; Shackelford \& Doremus, 2008). The combination of the mentioned qualities with a low neutron capture cross-section makes zirconium and its compounds indispensable components of construction materials for nuclear reactors, in particular, for the production of fuel element; it can also be a part of nuclear fuel (Lee et al., 2016; Savchenko et al., 2012). Zirconium is an alloying component of steels; its additives in the amount of $2 \mathrm{wt} . \%$ are used for deoxidization and removal of nitrogen and sulfur, for improving mechanical properties and workability (Baker, 2015; Xi, Li \& Yuan, 2006). In the jewelry industry, the metal zirconium, as well as zircon and fianit are used.

In recent decades, the field of technical applications of zirconium and its compounds has enlarged. Zirconium based alloys are often capable of volume amorphization; they attract researchers' attention due to the unique electrical, magnetic, and mechanical properties (a combination of high elasticity and plasticity with the properties of metal alloys) and in terms of the possibilities to study the nature of amorphous state (Fu, Sun \& Zhang, 2013; Louzgine-Luzgin \& Inoue, 2013; Qiao, Pelletier \& Casalini, 2013; Kulikova et al., 2015; Klumov, Ryltsev \& Chtchelkatchev, 2016). Zirconium can also be a part of high entropy alloys, known for their structural and phase formation features (Yurchenko et al., 2017; Zhao et al., 2017). Zirconium compounds (oxide, alloys, and salts) are widely used as catalysts, for example in redox reactions and isomerization reactions (Zhang \& Li, 2009; Molnar, 2011; Vining, Strunk \& Bell, 2011; Cao et al., 2016; Keitl et al., 2017); in the perfumery industry, they are used as components of antiperspirants (Shen and Nardello-Rataj 2009).

Zirconium-containing materials, including those obtained by sol-gel technology, are also used in other relevant fields as nanoparticles, coatings, tin films, fibers, and glasses to be used in electronics (Lonkar et al. 2011), alternative energy (Zyryanov et al., 2009; Bobryonok \& Predtechenskii, 2011), in medicine as nanocarriers of 
drugs and labels (Nagy et al. 2015; 2016), for producing new construction and functional materials (ASTM C1666/C1666M-08, 2015; Nemeryuk \& Lylina, 2017), for wastewater treatment (Da et al., 2016; Lu et al., 2016), for catalysis (Yasin et al. 2015), and so on. The low toxicity and high biological inertness of zirconium and its compounds account for their application in the production of medical instruments and implants (Lee et al., 2010; Katunar et al., 2017; Sequeira et al., 2017).

Zirconium is a part of highly ordered crystalline porous materials, metal-organic frameworks (MOFs) that became a new research hotspot in chemistry and materials science during the last few decades, which is mainly due to their exceptionally high surface area and tunable pores. MOFs with zirconium (Zr-MOFs) are notable for their outstanding stability in structure and composition; they usually include clusters of $\mathrm{Zr}_{\mathrm{x}} \mathrm{O}_{\mathrm{y}}$ and carboxylate ligands of different structures. Zr-MOF applications are catalysis, sorption and separation, energy storage and conversion, and creation of fluorescent and electrode materials (Bai et al. 2016).

Zirconium compounds play a significant part in analytical chemistry. In Table 1, some recent applications of zirconium compounds in different analytical methods are presented.

Table 1 shows that zirconium compounds are used to determine the diversity of inorganic and organic analytes, including toxic and biologically active compounds, as well as markers of cancer cells. The analytical application of zirconium compounds is due to their complexing, sorption, and ion-exchange properties (sample pretreatment, electrochemical, and luminescent methods of analysis). Ionites and sorbents based on zirconium compounds favorably differ from organic ion-exchange resins in having greater capacity, higher mechanical performance, and resistance to acids, alkalis and radiation, and greater selectivity and also retain ion-exchange properties up to $200^{\circ} \mathrm{C}$. Their properties strongly depend on the conditions of their preparation (temperature, formation rate, medium, and solution composition) (Lopez, Avnir \& Aegerter, 2003). Control over these conditions allows obtaining materials with the required analytical properties. For example, the amphoteric zirconium hydroxide in neutral and acidic media acts as an anion exchanger; however, in alkaline medium, it is capable of cation exchanging. Zirconium compounds can be used as sorbents at higher $\mathrm{pH}$ values than silicon compounds.

Solutions of zirconium salts are often used as chemical modifiers in electrothermal atomization atomic absorption spectrometry and electrothermal atomization molecular absorption spectrometry using novel highresolution continuum-source atomic absorption spectrometer (ET-AAS and ET-AMA).

Modifiers improve the quality of chemical analysis, primarily its sensitivity. The permanent modifiers based on zirconium or mixtures with platinum-group metals are usually made by repetitive additions of the solutions of corresponding salts into the graphite tube that undergoes heat treatment after each addition. Thus, treated tube can be used several times. The mechanism of zirconium modifying effect is still a subject of discussion. The main version is that in the graphite tube, zirconium forms a refractory carbide that protects the tube from the destructive effect of acids and prevents the formation of difficult atomized carbide of analyte (for example in the process of silicon or boron determination). It also catalyzes atomization processes (Volynsky 1998). The hypothesis of $\mathrm{ZrC}$ formation is confirmed, for example by electron microscope studies (Burylin et al. 2011). However, in some other studies, also based on the data of microscopy, X-ray diffraction analysis, and Raman spectroscopy, there is no evidence for the formation of zirconium carbide particles. Castro et al. (2009) believes that upon heating the salt solution together with nitric acid, $\mathrm{ZrO}_{2}$ is formed that covers the tube surface and protects it from damage. Both versions may be correct, and in each specific case, the composition of the mixture used in modification plays a critical role: either it is a solution of zirconium salts in hydrochloric acid or one in an oxidizing agent (for example nitric acid), either an organic solvent (Huang et al. 2014) or activated coal (Burylin et al. 2011) is added and so on. 

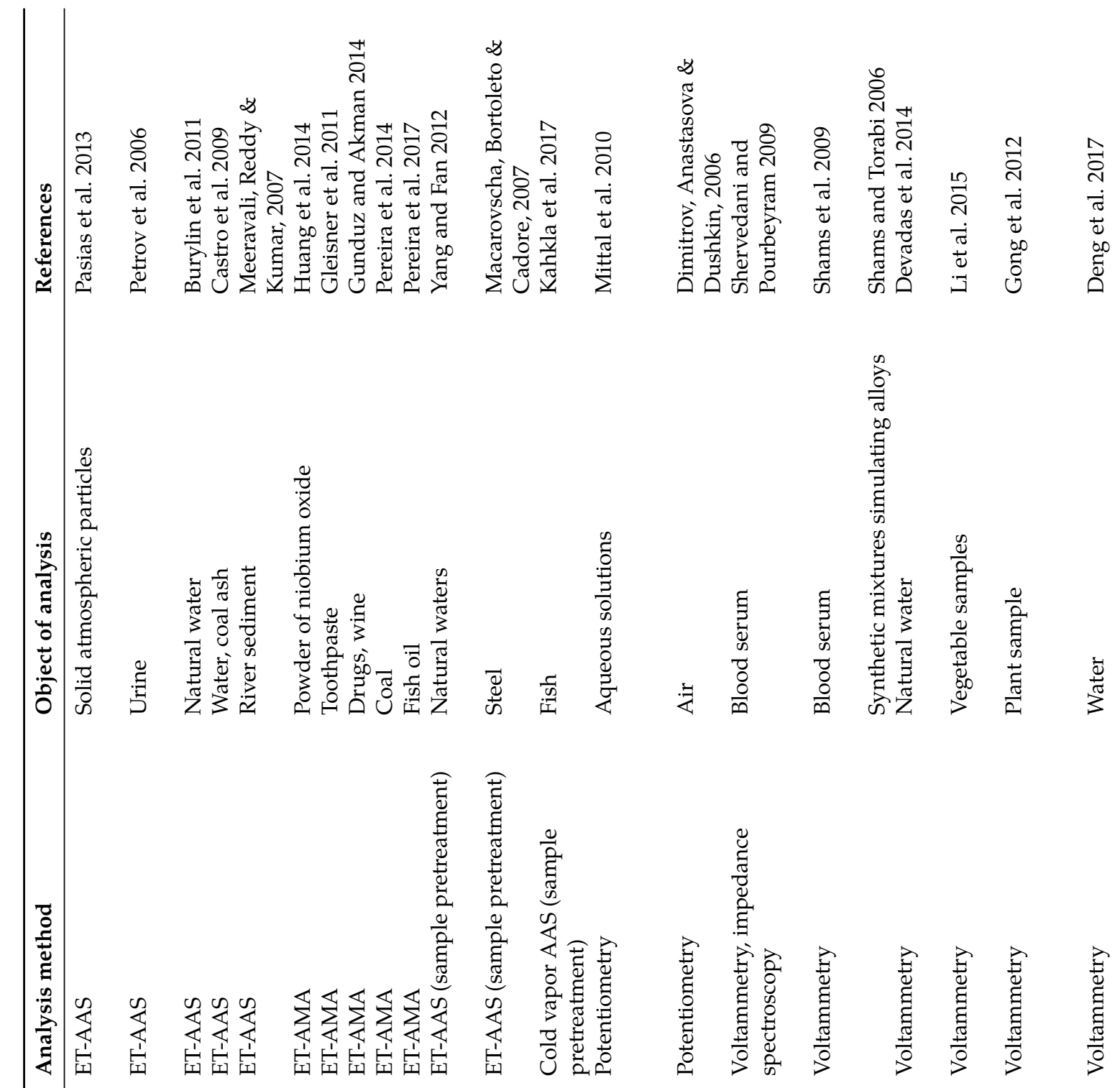

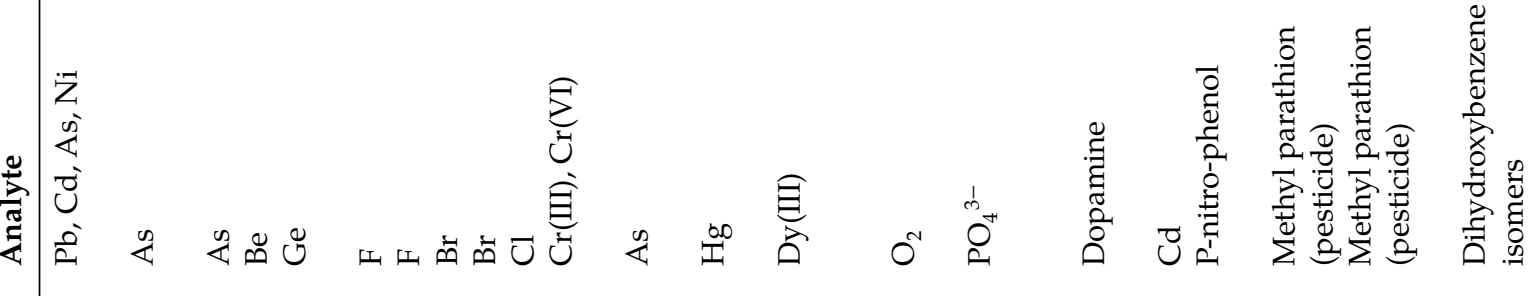

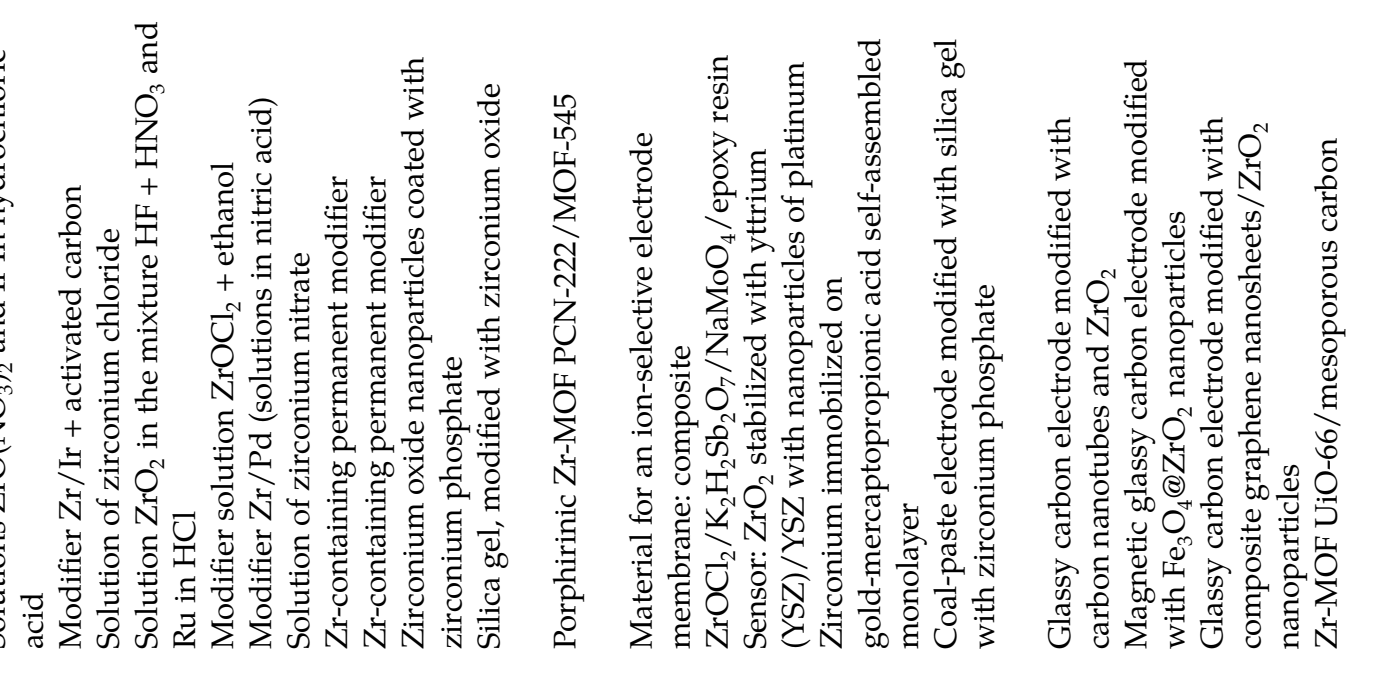




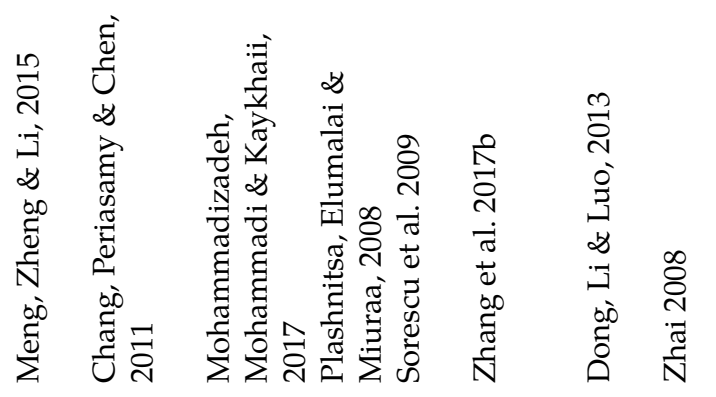

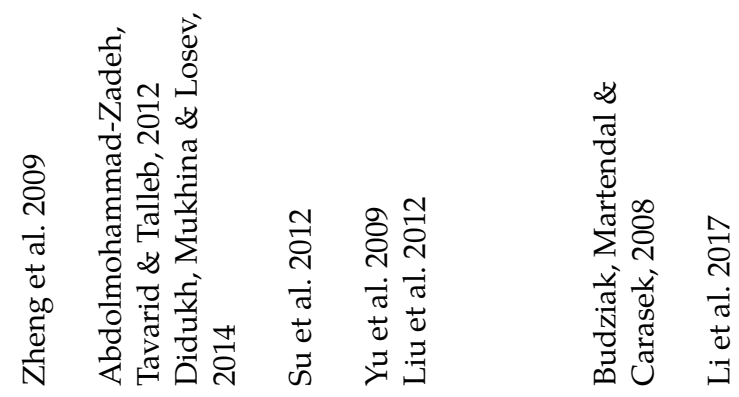
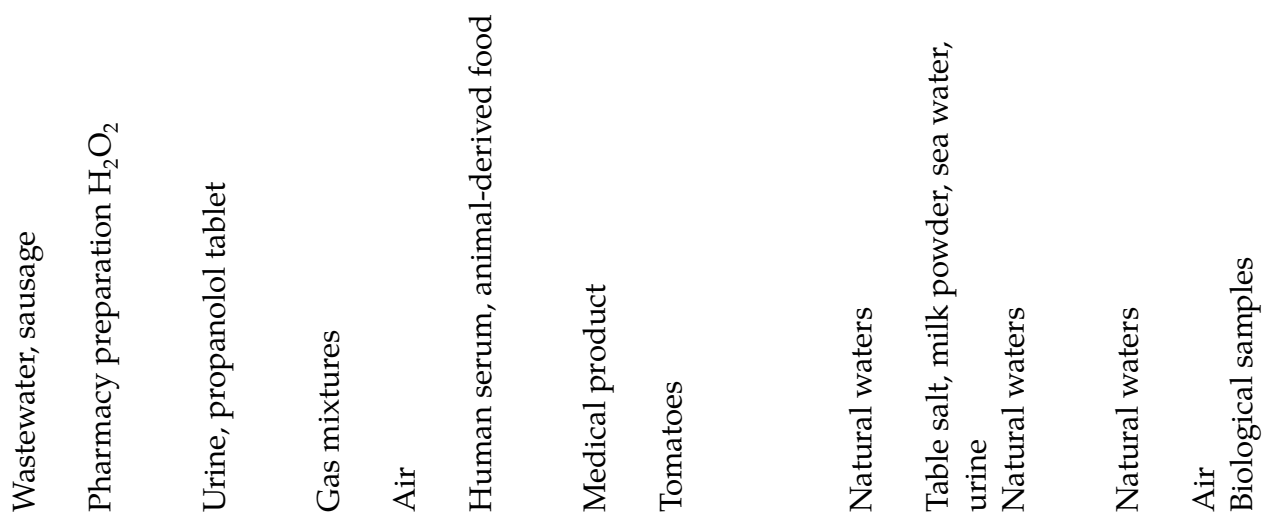

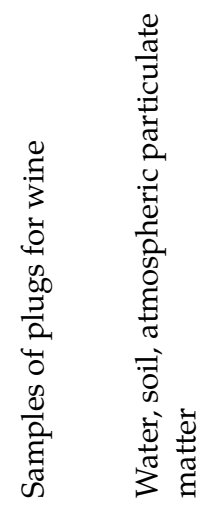

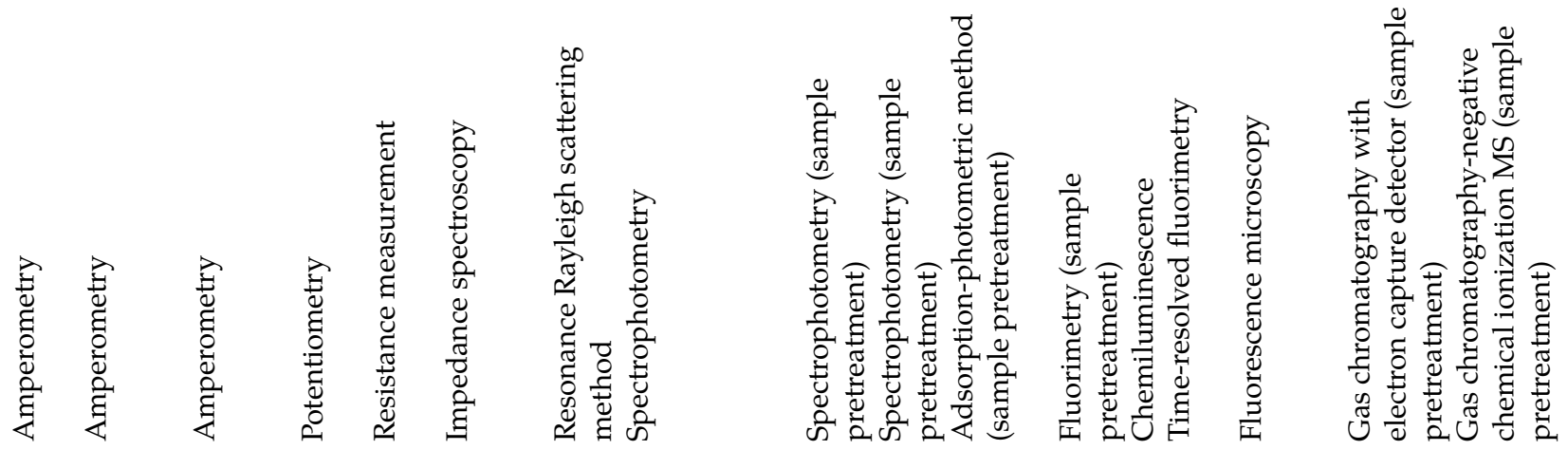

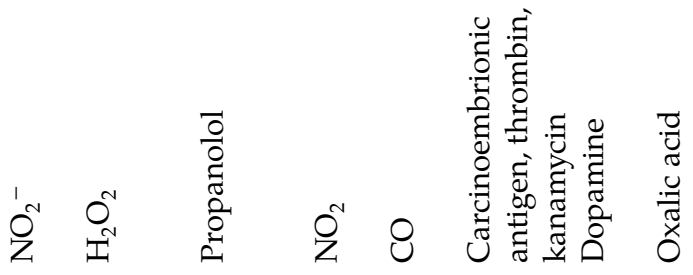

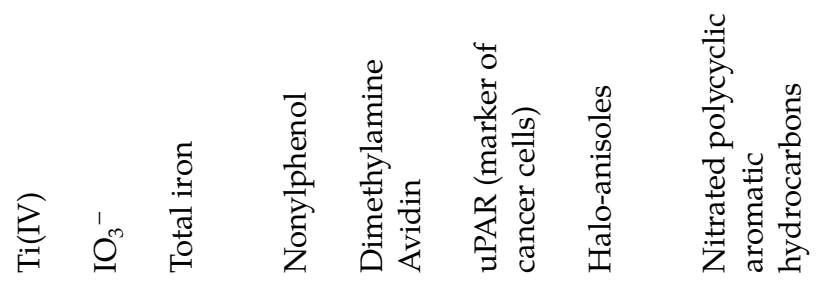

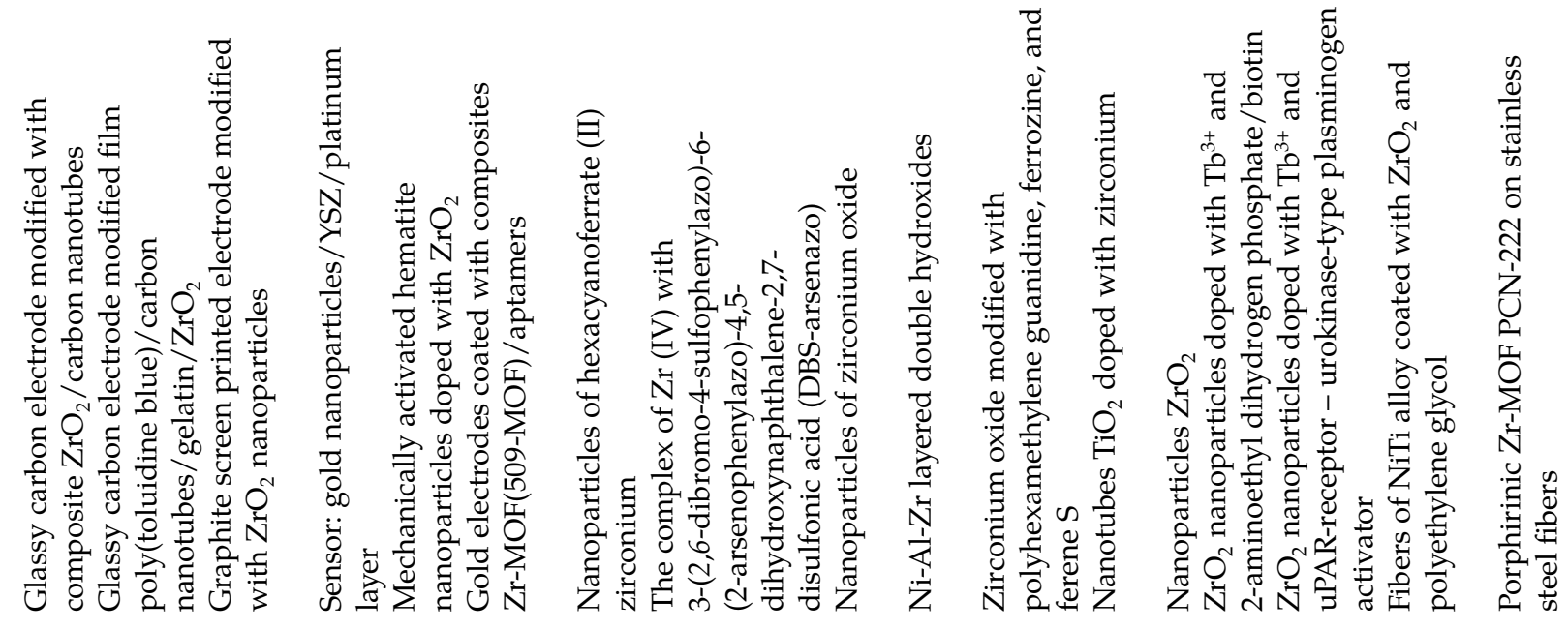




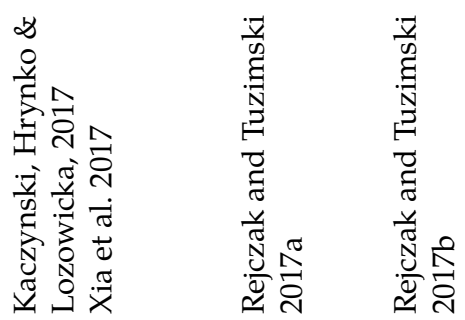

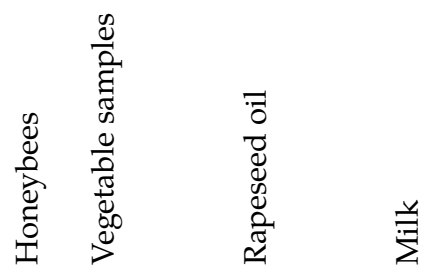

द्व

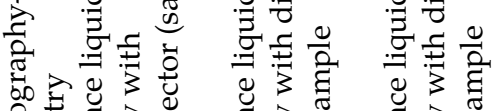

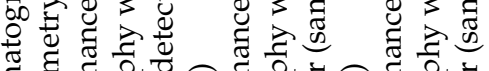

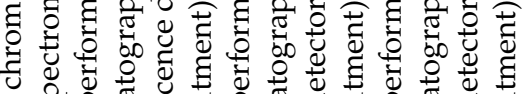
वै ठै.

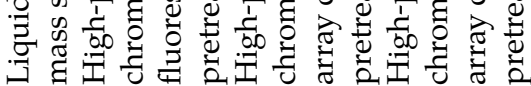

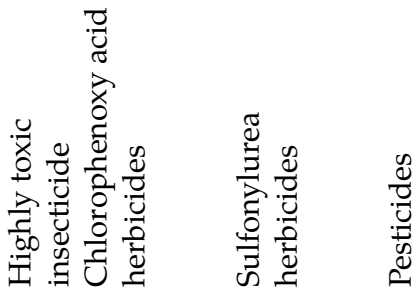

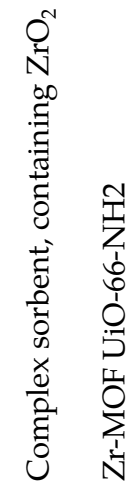

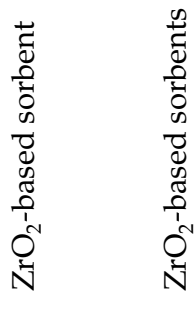


Recently, a number of works have been published in which the electroconductive, oxidation-reduction, and catalytic properties of zirconium-oxide-based materials are used to produce solid-state sensors, in particular, for the determination of some gaseous substances in air (Dimitrov, Anastasova \& Dushkin, 2006; Plashnitsa, Elumalai \& Miuraa, 2008; Sorescu et al., 2009; Yu et al., 2009; Devadas et al., 2014; Meng, Zheng \& Li, 2015). Similar properties arise in zirconium oxide, mainly when impurities with a valence different from that of zirconium are introduced (yttrium, calcium oxides, etc.) and when the vacancies in crystal lattice responsible for ionic conductivity are formed (Borik et al., 2017; Gregori, Merkle \& Maier, 2017).

The data presented in Table 1 demonstrate that, in the analytical application of zirconium compounds, there appear some modern trends of the use of nanoparticles, carbon nanotubes modified in different ways. This is particularly due to the fact that such materials have a large surface area. Besides, a substance in the form of nanoparticles is more evenly dispersed in the mass of composites used, for example in the production of electrode materials. The nanosized state of zirconium dioxide stabilizes its "high-temperature" modifications (cubic, tetragonal) without introducing any additives (Zavodinsky \& Chibisov, 2006; Yu et al., 2009), which contributes to an improvement in its performance characteristics, in particular, its electrical conductivity.

Thus, it can be stated that zirconium is actively used in analytical practice due to the valuable properties of its compounds.

The widespread use of zirconium-containing materials requires the improvement of existing methods and the development of some new ones for controlling zirconium in all above listed materials as well as in its raw materials and environmental objects. It is necessary to control possible contaminants that originated from the production and operation of zirconium-containing materials. The control over zirconium content in soils can serve to monitor the anthropogenic impact on ecosystems, for example the pollution caused by dust and smoke emissions of coal-fired power plants (coal contains a significant amount of zirconium (Swaine 1990). Increased zirconium content against its abundance in the Earth's crust (in soil - $400 \mathrm{mg} \cdot \mathrm{kg}^{-1}$ ) (Bowen 1979) indicates that the territory has been contaminated.

Although zirconium and its insoluble compounds are considered to be of low toxicity, and their contents are not standardized for drinking and surface waters, it is believed that aerosols containing zirconium can have a fibrogenic effect on human body, and zirconium-containing perfume preparations can cause skin inflammation (Lee et al. 2010). There is an opinion expressed that zirconium is phytotoxic and suppresses plant growth, so its control in environmental objects is necessary (Shahid et al. 2013). Pollution of surface, groundwater, and soil by zirconium can occur in incidents at nuclear power plants and nuclear waste depositories, since some amount of radioactive zirconium isotopes are formed during the splitting of ${ }^{235} \mathrm{U}$ and ${ }^{239} \mathrm{Pu}$ and also when fuel element cans are activated by thermal neutrons (Osváth et al. 2011). The radioactive zirconium isotope ${ }^{93} \mathrm{Zr}$ is capable of producing a long-term pollution effect due to its long half-life (1.53.10 ${ }^{6}$ years).

Control of zirconium content in rocks is necessary not only for the evaluation of its reserves but also for the tasks of geochemistry. Data on the content of trace elements, in particular zirconium, provide unique information on geological processes (including volcanic, sedimentary, etc.) occurring on Earth (Bayon et al. 2009); because zirconium compounds in rock are resistant to the influence of land waters, they remain intact for a long time. Zirconium is also one of the indicator elements that allow tracking the movement of seawater masses and their pollution (Firdaus et al. 2007).

Thus, the number of objects demanding the determination of zirconium content is great, but at present there are no works that present generalized information on modern methods for zirconium determination. Some sufficiently detailed reviews published in the 1960s and 1970s (Elinson \& Petrov, 1965; Mukherji, 1970) do not, naturally, include the descriptions of such methods as atomic absorption, inductively coupled plasma atomic emission spectroscopy, mass spectrometry (MS), etc., as they began to be developed in the decades that followed. Since then, only one review has been published about the spectrophotometric techniques for zirconium determination, developed between 1991 and 2004 (Dalawat, Chauhan \& Goswami, 2005).

Obviously, there is an urgent task of systematizing modern information on the analytical chemistry of such important element as zirconium which is widely spread in various spheres of human activity.

\section{Methods for zirconium determination}

\section{Gravimetry and titrimetry}

Classical methods of analysis - gravimetry and titrimetry - are still relevant for the determination of zirconium and are widely represented in current regulatory documentation (for example ASTM D3969-01, 2012; ISO 21079-2:2008, 2008). They are used for high-precision determination of zirconium average and high contents (from $n \cdot 10^{-2}-n \cdot 10 \mathrm{wt} . \%$ and up to $90 \mathrm{wt} . \%$ ) in alloys, steels, refractory materials and raw materials for them, fluxes, zirconium minerals, and concentrates. For example, in Pechishcheva et al. (2017), gravimetry was 
used to determine 40-60 wt.\% zirconium in binary amorphous alloys $\mathrm{Cu}_{100-\mathrm{x}} \mathrm{Zr}_{\mathrm{x}}$, whereas in Yildiz (2017), it was applied for the determination of about $30 \mathrm{wt} . \% \mathrm{Zr}$ in ceramic-based adhesive.

\section{Electrochemical methods}

This group of methods for zirconium determination has been presented in recent works as voltammetry, potentiometry, impedance spectroscopy, and differential pulse polarography. The techniques are not multielement; as a rule, only zirconium is determined from a single sample. The equipment is relatively cheap, simple, portable, and acceptable in the field; the techniques are easily automated. It is necessary to exactly control the $\mathrm{pH}$ in electrochemical methods for zirconium determination, as well as in photometric methods. This is due to the fact that complex compounds of zirconium with organic ligands containing acidic and basic groups are often used in electrochemical methods, and the electrode reactions of organic compounds usually include $\mathrm{H}^{+}$-ion.

Voltammetric methods for zirconium determination are based on measuring the intensity of current for the reduction/oxidation of electroactive complexes of zirconium with organic ligands. Due to the negative reduction potential of zirconium (IV) in aqueous solutions $(-1.69 \mathrm{~V})$, zirconium is difficult to determine by traditional voltammetry.

A brief review of electrochemical methods for zirconium determination is presented in Table 2.

Table 2: Electrochemical techniques for the zirconium determination.

\begin{tabular}{|c|c|c|c|c|}
\hline Method & Analyzed object & $\begin{array}{l}\text { Determined contents, } \\
\text { detection limit }\end{array}$ & Features of the procedure & References \\
\hline Voltammetry & $\begin{array}{l}\text { Synthetic } \\
\text { solutions }\end{array}$ & $\begin{array}{l}6 \cdot 10^{-7} \pm 4 \cdot 10^{-6} \mathrm{~mol} \cdot \mathrm{l}^{-1} \\
\text { Detection limit } 0.025 \\
\mathrm{mg} \cdot \mathrm{l}^{-1}\end{array}$ & $\begin{array}{l}\text { Reduction of } \mathrm{Zr} \text {-complex } \\
\text { with a calcon on a mercury } \\
\text { dropping electrode } \\
\mathrm{Cu}, \mathrm{Fe}, \mathrm{Mn} \text { in equal } \\
\text { concentrations, } \mathrm{Zn}, \mathrm{Cd}, \mathrm{Mg} \text { in } \\
\text { 100-fold excess do not } \\
\text { interfere }\end{array}$ & $\begin{array}{l}\text { Levytska, Bilyk } \\
\& \text { Dubenska, } \\
2006\end{array}$ \\
\hline \multirow[t]{2}{*}{$\begin{array}{l}\text { Adsorption } \\
\text { inversion } \\
\text { voltammetry }\end{array}$} & Ore samples & $\begin{array}{l}1 \cdot 10^{-9}-10^{-7} \mathrm{~mol} \cdot \mathrm{l}^{-1} \\
\text { Detection limit } 0.03 \\
\mu \mathrm{g} \cdot \mathrm{l}^{-1}\end{array}$ & $\begin{array}{l}\text { Zr-complex with alizarin red } \\
\mathrm{S} \text { is accumulated on a carbon } \\
\text { paste electrode at } 0.20 \mathrm{~V} \text {, then } \\
\text { it is oxidized } 0.20-0.80 \mathrm{~V} \\
1000 \text {-fold excesses of } \mathrm{Ca}, \mathrm{Mg} \text {, } \\
\mathrm{Ba}, \mathrm{Ni} \text { and } \mathrm{Cd} \text { do not interfere }\end{array}$ & $\begin{array}{l}\text { Li, Zhao \& } \\
\text { Huang, } 2007\end{array}$ \\
\hline & Seawater & $\begin{array}{l}(0.05-4.9) \cdot 10^{-9} \mathrm{~mol} \cdot \mathrm{l}^{-1} \\
\text { Detection limit } 0.4 \\
\mathrm{ng} \cdot \mathrm{l}^{-1}\end{array}$ & $\begin{array}{l}\text { Zr triple complex with } \\
\text { cupferron, oxalate ion and } \\
\text { diphenylguanidine. } \\
\text { Adsorption on mercury } \\
\text { electrode at } 0.600 \mathrm{~V} \text {, then } \\
\text { scanning from } 0.60 \text { to } 1.10 \mathrm{~V} \text {. } \\
\text { Influence of high content of } \\
\mathrm{V}, \mathrm{Ti}, \mathrm{Hf}\end{array}$ & $\begin{array}{l}\text { Schneider et al. } \\
2015\end{array}$ \\
\hline $\begin{array}{l}\text { Impedance } \\
\text { spectroscopy }\end{array}$ & $\begin{array}{l}\text { Synthetic } \\
\text { solutions, river } \\
\text { and tap water }\end{array}$ & $\begin{array}{l}1.0 \cdot 10^{-9}-5.0 \cdot 10^{-5} \\
\mathrm{~mol} \cdot \mathrm{l}^{-1} \\
\text { Detection limit } 0.07 \\
\mu \mathrm{g} \cdot \mathrm{l}^{-1}\end{array}$ & $\begin{array}{l}\text { Zr is preliminarily adsorbed } \\
\text { on gold electrode modified } \\
\text { with a monolayer of } \\
\text { cystamine functionalized } \\
\text { with a hydroxamic acid } \\
\text { derivative }\end{array}$ & $\begin{array}{l}\text { Shervedani and } \\
\text { Bagherzadeh } \\
2009\end{array}$ \\
\hline \multirow[t]{3}{*}{ Potentiometry } & $\begin{array}{l}\text { Alloys, tape and } \\
\text { waste water } \\
\text { samples }\end{array}$ & $\begin{array}{l}1.0 \cdot 10^{-7}-1.0 \cdot 10^{-1} \\
\mathrm{~mol} \cdot \mathrm{1}^{-1} \\
\text { Detection limit } 1.6 \\
\mu \mathrm{g} \cdot \mathrm{l}^{-1}\end{array}$ & $\begin{array}{l}\text { Membrane of } \\
\text { the developed sensor contains } \\
\text { bis(diphenylphosphino)ferrocer } \\
\text { that forms a complex with } \mathrm{Zr}\end{array}$ & $\begin{array}{l}\text { Gholivand, } \\
\text { Babakhanian \& } \\
\text { đoshaghani, } \\
2007\end{array}$ \\
\hline & $\begin{array}{l}\text { Synthetic } \\
\text { solutions }\end{array}$ & $\begin{array}{l}1.8 \cdot 10^{-4}-2.6 \cdot 10^{-3} \\
\mathrm{~mol} \cdot \mathrm{l}^{-1}\end{array}$ & $\begin{array}{l}\text { Membrane of the developed } \\
\text { sensor contains thoron that } \\
\text { forms a complex with } \mathrm{Zr}\end{array}$ & Arida 2008 \\
\hline & Alloys & $5-28 \mu \mathrm{g} \cdot l^{-1}$ & $\begin{array}{l}\text { Membrane of the developed } \\
\text { sensor contains alizarin red S } \\
\text { that forms a complex with } \mathrm{Zr}\end{array}$ & $\begin{array}{l}\text { Gupta, Goyal \& } \\
\text { Sharma, } 2009\end{array}$ \\
\hline
\end{tabular}


Direct voltammetry is presented in Levytska, Bilyk, and Dubenska (2006), where zirconium in the range $6 \cdot 10^{-7} \pm 4 \cdot 10^{-6} \mathrm{~mol} \cdot \mathrm{l}^{-1}$ was determined by using the reduction of zirconium complex with a calcon on a mercury dropping electrode with a detection limit of $3 \cdot 10^{-7} \mathrm{~mol} \cdot \mathrm{l}^{-1}\left(0.025 \mathrm{mg} \cdot \mathrm{l}^{-1}\right)$. The object of analysis was model solutions containing copper, iron, and manganese in concentrations equal to the concentrations of zirconium, and for zinc, cadmium, and magnesium in 100-fold excess, those components did not interfere.

The adsorption inversion voltammetry (voltammetry with preliminary accumulation) is characterized by a lower detection limit. A technique for determining zirconium in ores using this method is described in Li, Zhao, and Huang (2007) for zirconium content in the sample solution $1 \cdot 10^{-9}-10^{-7} \mathrm{~mol} \cdot \mathrm{1}^{-1}$. The zirconium complex with alizarin red $S$ is first accumulated on a carbon paste electrode at a potential of $0.20 \mathrm{~V}$, then the complex is oxidized as the potential increases to $0.80 \mathrm{~V}$, and the corresponding voltammogram is obtained. The detection limit of zirconium is $3 \cdot 10^{-10} \mathrm{~mol} \cdot \mathrm{l}^{-1}\left(0.03 \mu \mathrm{g} \cdot \mathrm{l}^{-1}\right)$. The procedure is sufficiently selective (1000-fold excesses of calcium, magnesium, barium, nickel, and cadmium do not interfere).

The same version of voltammetry was used for zirconium determination in seawater as a complex simultaneously with three ligands: cupferron, oxalate ion, and diphenylguanidine (Schneider et al. 2015). The technique is characterized by a wide range of detectable concentrations of $(0.05-4.9) \cdot 10^{-9} \mathrm{~mol} \cdot \mathrm{1}^{-1}$ and low detection limit of $4.3 \cdot 10^{-12} \mathrm{~mol} \cdot \mathrm{l}^{-1}\left(0.4 \mathrm{ng} \cdot \mathrm{l}^{-1}\right)$. The determination of zirconium can be successfully carried out against the background of a high-salt matrix. There is an influence of titanium, vanadium, and hafnium at high contents on the seawater. The interfering effect of organic compounds is removed by ultraviolet irradiation of sample solutions. For zirconium determination by cyclic voltammetry, Shervedani and Pourbeyram (2009) attempted to use a gold electrode modified with a monolayer of cystamine functionalized with a hydroxamic acid derivative. In acidic solutions, the modified electrode demonstrates a good response to the presence of $1.0 \cdot 10^{-9}-5.0 \cdot 10^{-5} \mathrm{~mol} \cdot \mathrm{l}^{-1} \mathrm{zir}-$ conium (it forms a complex with hydroxamic acid). However, the reproducibility of the signal was not achieved, probably due to the irreversible formation of $\mathrm{ZrO}_{2}$ in the monolayer. Therefore, the authors decided to apply the created sensor to zirconium determination using another electrochemical method - the impedance spectroscopy. The impedance (ac impedance) of a system consisting of the developed electrode, auxiliary platinum, and silver chloride electrodes in para-benzoquinone at a fixed current frequency is proportional to zirconium concentration. Zirconium, preliminarily adsorbed on the working electrode from the analyzed solution, interacts with a monolayer on the surface of the indicator electrode and inhibits charge transfer. This version of the technique resulted in signal reproducibility. The detection limit of $7 \cdot 8 \cdot 10^{-10} \mathrm{~mol} \cdot \mathrm{1}^{-1}\left(0.07 \mu \mathrm{g} \cdot \mathrm{l}^{-1}\right)$ of zirconium has been reached. A lot of ions of single-trivalent metals do not influence the results of determination. This technique is used for the analysis of synthetic solutions and river and tap water (Shervedani and Bagherzadeh 2009).

There is a variety of ion-selective electrodes recently developed for the determination of zirconium. For example, in the analysis of tap water, wastewater, and aluminum alloys, the electrode filled with zirconyl chloride solution is used. Its membrane is made of polyvinyl chloride, plasticizer-tris(2-ethylhexyl)phosphate, ligandbis(diphenylphosphino)ferrocene, and sodium tetraphenylborate (Gholivand, Babakhanian \& Joshaghani, 2007). The sensor is highly selective and allows the determination of $1.0 \cdot 10^{-7}-1 \cdot 10^{-1} \mathrm{~mol} \cdot 1^{-1}$ zirconium in the presence of many metals. The detection limit is $1.8 \cdot 10^{-8} \mathrm{~mol} \cdot \mathrm{l}^{-1}\left(1.6 \mu \mathrm{g} \cdot \mathrm{l}^{-1}\right)$.

In Arida (2008) and Gupta, Goyal, and Sharma (2009), the authors describe some examples of the application of electrodes selective to organic reagents for the indirect determination of zirconium, which forms a complex with them. So, a sensor with a membrane containing thoron (4-((2-arsonophenyl)azo)-3-hydroxy-2,7naphthalenedisulfonic acid) was used for determining $1.8 \cdot 10^{-4}-2.6 \cdot 10^{-3} \mathrm{~mol} \cdot \mathrm{l}^{-1}$ of zirconium (Arida 2008). A sensor with membrane based on alizarin red $S$ was used for determining $5-28 \mu \mathrm{g} \cdot 1^{-1}$ zirconium in solutions of alloys (Gupta, Goyal \& Sharma, 2009).

\section{Spectroscopic methods}

\section{Methods of molecular spectroscopy}

Spectrophotometry is also widely used in the analytical chemistry of zirconium due to its simplicity and inexpensive equipment (see Table 3). 


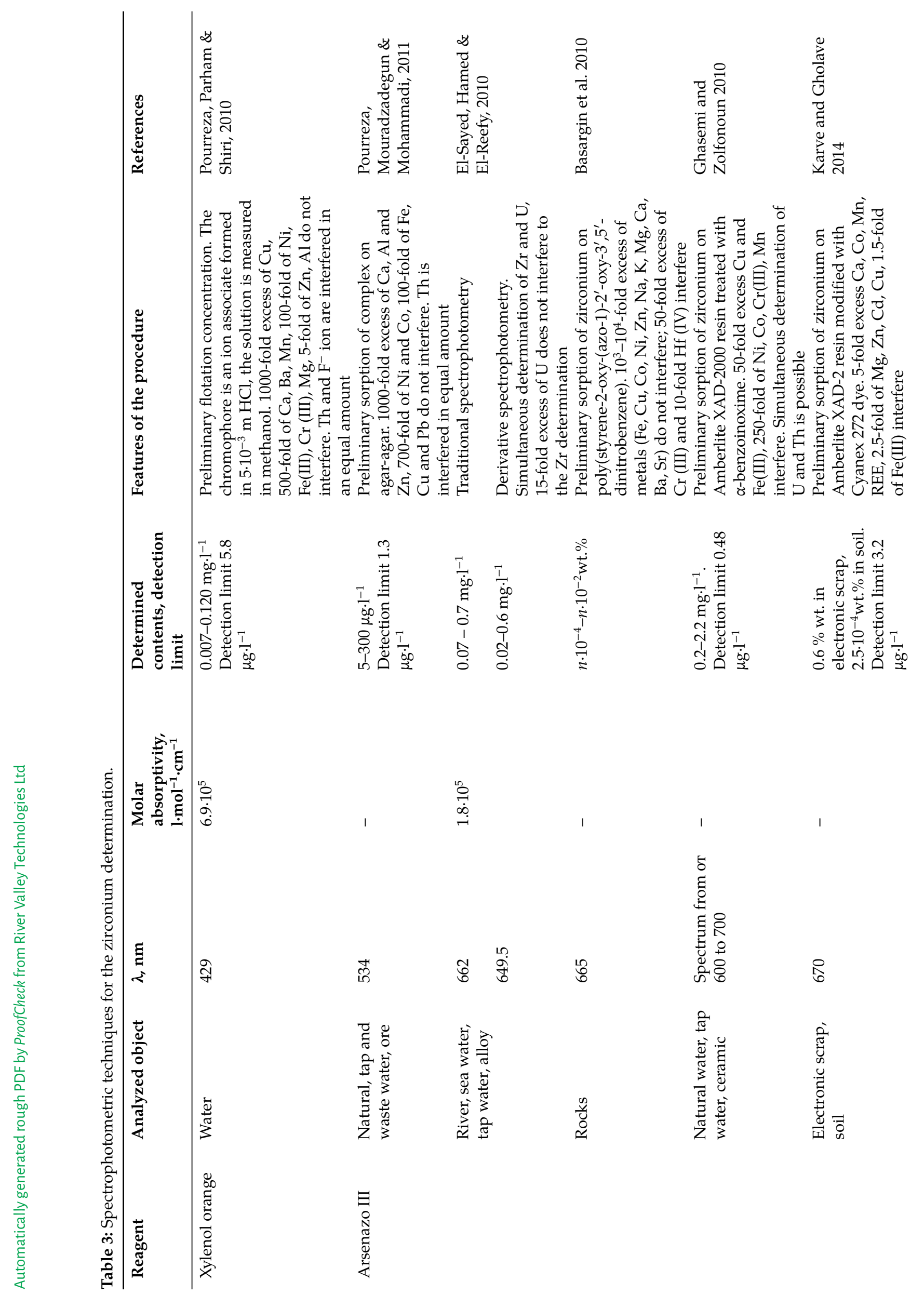




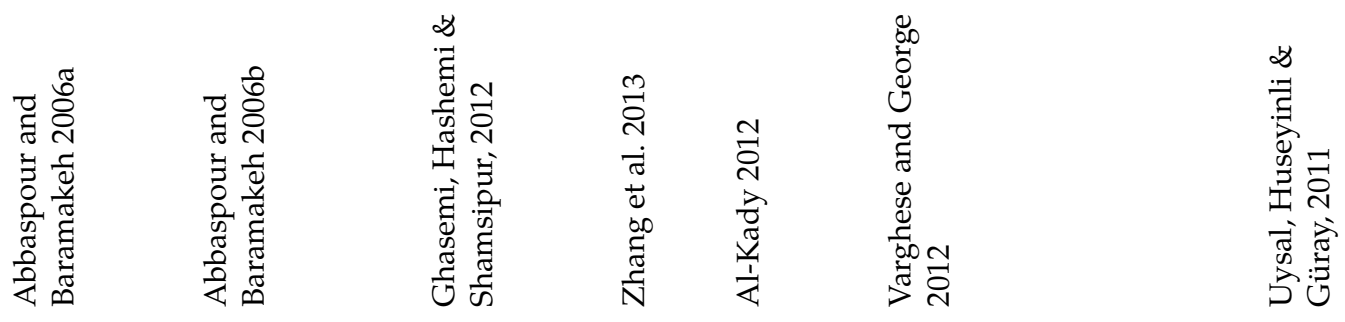

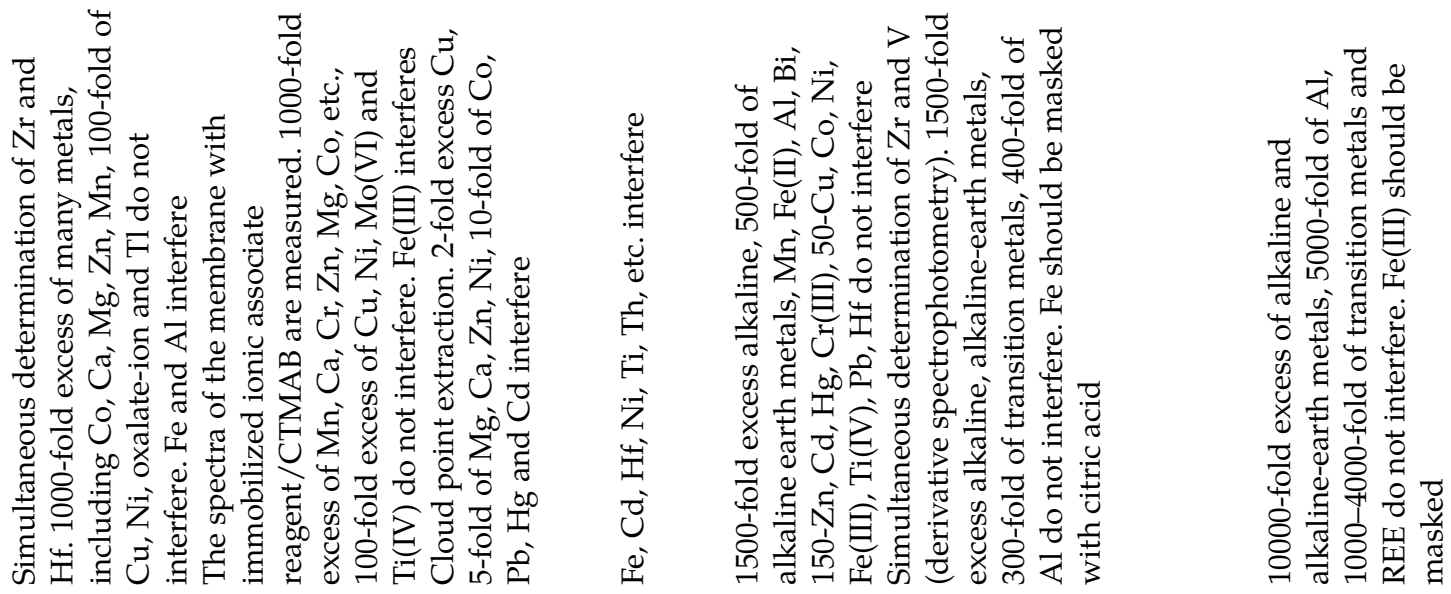

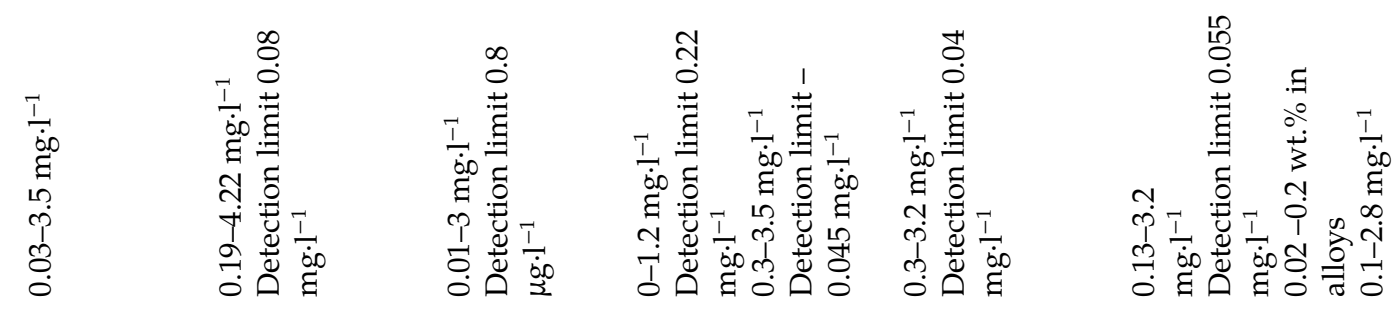

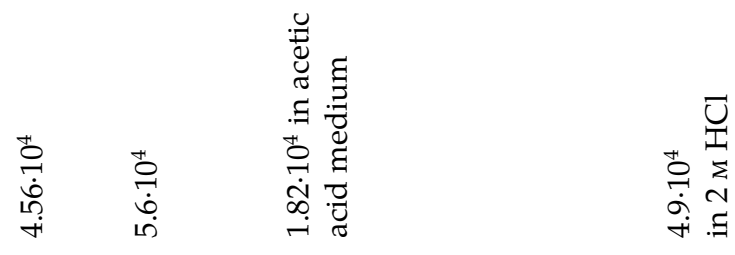

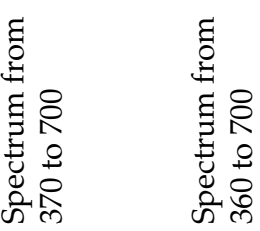

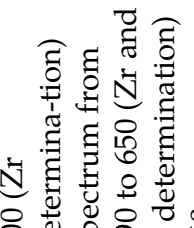
疍
ถั

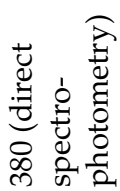

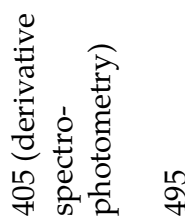

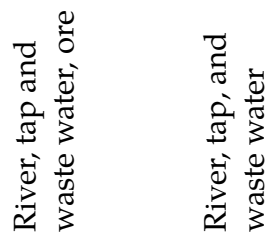

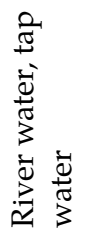

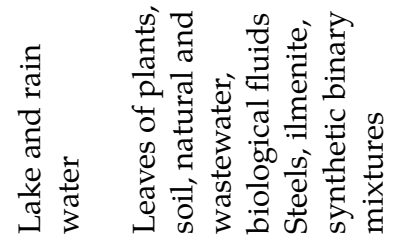

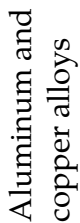

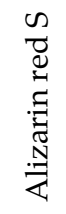

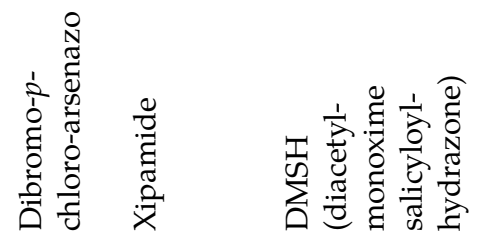

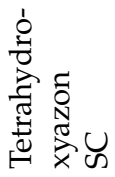




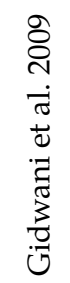

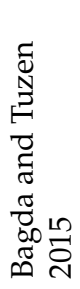

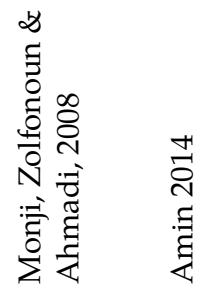

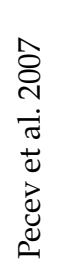

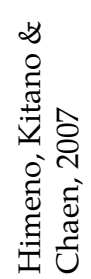

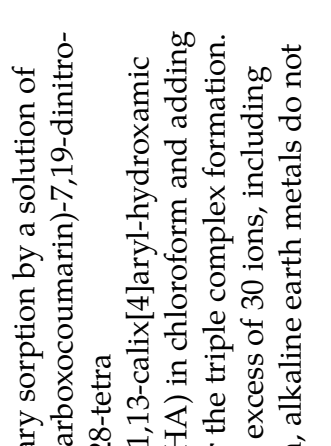

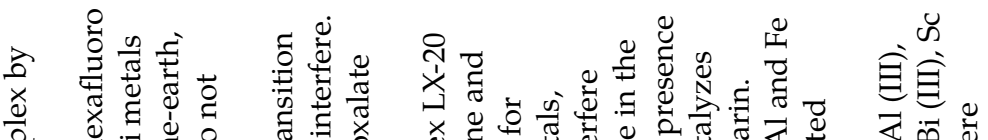

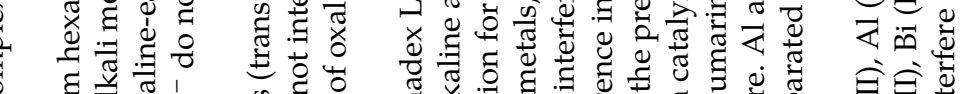

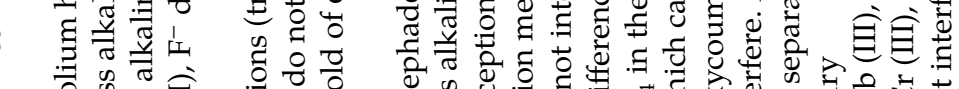

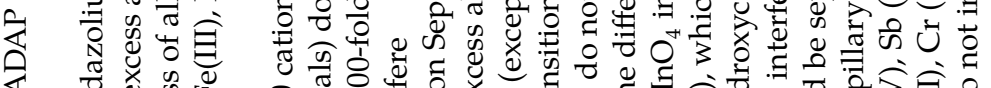

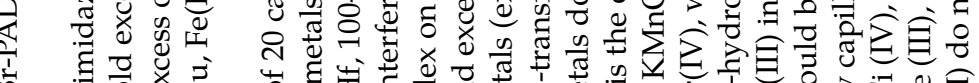

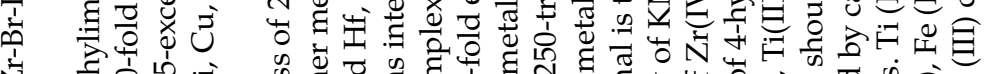

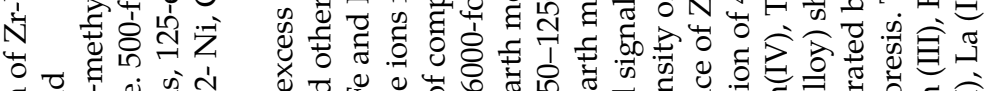

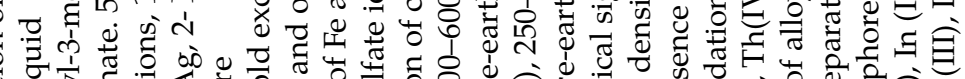

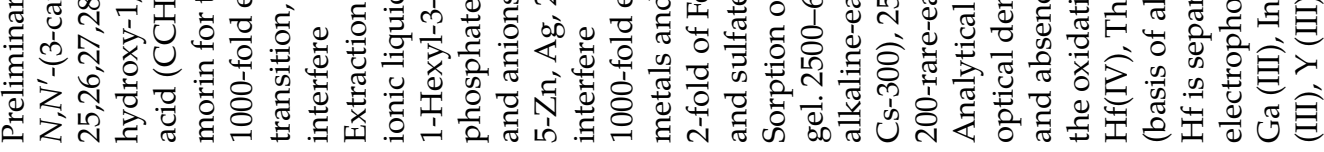

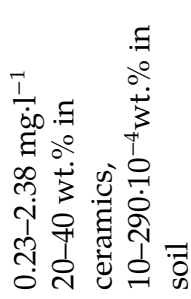

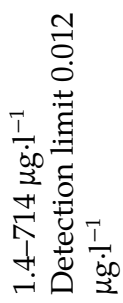

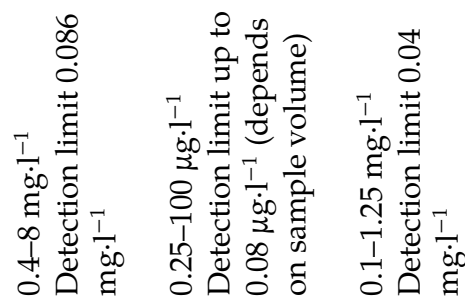

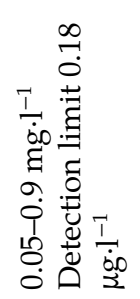

$\stackrel{+}{0}$
$\stackrel{1}{\dot{0}}$
$\stackrel{\infty}{\infty}$

孚

$\stackrel{\infty}{i n}$

สิ ถั่

씅

$\stackrel{\infty}{\stackrel{\infty}{N}}$

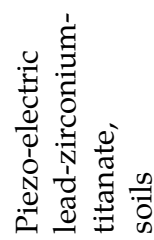

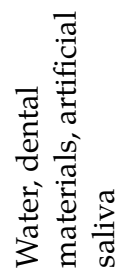

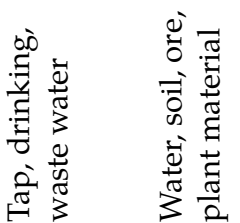

$\infty$
$\frac{0}{\sigma}$
$\frac{1}{4}$
$\frac{1}{4}$

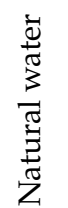

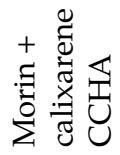

究

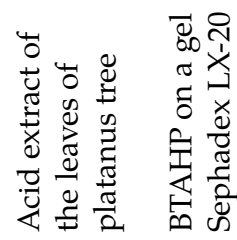

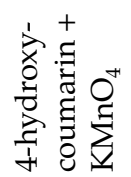

$\sum^{1}$ 
Spectrophotometric determination of zirconium is often carried out using triphenylmethane dyes and reagents containing azo groups, for example xylenol orange, arsenazo III, and alizarin red S. But often, the zirconium determination with their application needs preliminary zirconium separation from numerous interfering components or masking the influence of interfering components. Modern modifications of the techniques using these reagents are mainly aimed at increasing sensitivity, achieving smaller detection limits by concentrating, improving selectivity, or the possibility of determination of other components together with zirconium.

For example, the flotation concentration was carried out to increase the sensitivity of photometric determination of zirconium with xylenol orange in water samples (Pourreza, Parham \& Shiri, 2010). In this work, the use of the ionic associate of zirconium with xylenol orange in a medium of $5 \cdot 10^{-3} \mathrm{M}$ hydrochloric acid is described for the metal determination. The analytical procedure involves the associate isolation at the interface of aqueous solution and n-hexane, its dissolving in a small amount of methanol, and measuring the optical density at $429 \mathrm{~nm}$. The detection limit is $5.8 \mu \mathrm{g} \cdot \mathrm{1}^{-1}$. For example and 1000 -fold excess of copper, 500 -fold excess of manganese, and 100-fold Ni (II), Cr (III), Fe (III) do not interfere with the determination.

Many researchers are searching to improve the techniques using arsenazo III. The work of El-Sayed, Hamed, and El-Reefy (2010) presents a spectrophotometric technique with arsenazo III in two variants. The first variant is the traditional spectrophotometry using an aqueous-organic medium (water/ethanol/dimethylformamide) to increase the sensitivity as well as thermal and temporal stability of the complex. The second variant is a derivative spectrophotometry to determine zirconium (IV) simultaneously with uranium (VI), also forming a complex with arsenazo III. The so-called "zero-crossing" method was used, with the calibration plot for zirconium being built for wavelength at which the plot of the first derivative of the optical density for uraniumarsenazo III complex crossed the axis. The technique was applied to the analysis of tap water, seawater, and river water samples, as well as simulated mixture modeling an alloy containing uranium, molybdenum, copper, zirconium, and other components.

In a number of works, the preliminary concentration of zirconium or its complex with arsenazo III on sorbents of various types is used (Basargin et al., 2010; Ghasemi \& Zolfonoun, 2010; Pourreza, Mouradzadegun \& Mohammadi, 2011; Karve \& Gholave, 2014). Thus, the high selectivity of zirconium determination against the background of $10^{3}-10^{4}$-fold mass excesses of many transition, alkaline, alkaline-earth, and rare-earth metals is demonstrated after its concentration on the polymeric chelate sorbent - polystyrene-2-hydroxy-(azo-1)-2'hydroxy-3', $5^{\prime}$-dinitrobenzene (Basargin et al. 2010). In the work of Ghasemi and Zolfonoun (2010), the detection limit of zirconium was $0.48 \mu \mathrm{g} \cdot \mathrm{l}^{-1}$ when using the ion-exchange resin Amberlite XAD-2000 for the concentration treated with $\alpha$-benzoinoxime, but the selectivity was not as high as in the previous procedure - copper and iron (III) influence the determination of zirconium at 50-fold excess. To solve the problem of overlapping absorption spectra during zirconium determination alongside with thorium and uranium in waters and ceramics, the authors used a multivariate calibration by orthogonal signal correction - the partial least squares method (Otto \& Wegscheider, 1989; Wold et al., 1998). As initial information, the absorption spectra obtained in a digital form for complexes of all three analytes with arsenazo III in the range of 600-700 nm were used. Also, the spectra of so-called "training" artificial mixtures containing various known concentrations of zirconium, uranium, and thorium were used. The spectra analysis by a constructed model allowed the introduction of correction coefficients until the specified accuracy was achieved.

Such an approach with multivariable calibration and several other chemometric algorithms is applied to simultaneous determination of zirconium and metals in ore and water samples using alizarin red $S$, for example zirconium with hafnium (the algorithm "artificial neural network," package MATLAB 5.3, Neural Network Toolbox) (Abbaspour and Baramakeh 2006a) or zirconium with uranium (the method of partial least squares, MATLAB 7.2, PLS-Toolbox) (Ghasemi, Hashemi \& Shamsipur, 2012). Ghasemi, Hashemi, and Shamsipur (2012) also used procedure concentration of analytes (the so-called "cloud-point extraction") to reduce the detection limit. After the addition of a nonionic surfactant (Triton-X-114) to the test solution with alizarin red S, and heating to $45^{\circ} \mathrm{C}$, the complex compounds of zirconium and hafnium pass into a phase enriched with surfactants. The "artificial neural network" algorithm was used for analyzing the absorption spectra of a transparent membrane on which the ion associate alizarin red S/cationic surfactant (cetyltrimethylammonium bromide) is immobilized (Abbaspour and Baramakeh 2006b).

In recent years, a number of new photometric reagents for the determination of zirconium were also developed. The use of some of them increased the selectivity and sensitivity of zirconium determination, compared with "classical" reagents. Thus, for the determination of zirconium in water, the arsenazo III derivative - dibromine-p-chlorine-arsenazo - forming a complex with zirconium 1:3, was used (Zhang et al. 2013). Although the technique is not selective, the authors improved the sensitivity of zirconium determination by almost four times compared with the "prototype" under a similar $\mathrm{pH}$.

For the photometric zirconium determination in biological and environmental samples, the reagent xypamide-4-chlorine- $N$-(2,6-dimethylphenyl)-2-hydroxy-5-sulfamoylbenzamide, forming a complex with zirconium 1:1, was synthesized (Al-Kady 2012). Compared with xylenol orange, this reagent provides greater 
sensitivity and better selectivity: 1500-fold mass excess of alkaline; 500-fold alkaline earth metals, manganese, iron (II), aluminum, bismuth, 150-fold zinc, cadmium, mercury, and chromium (III); and 50-fold copper, cobalt, nickel, iron (III), titanium (IV). Lead and hafnium do not interfere.

Diacetyl monoxime salicyl hydrazone (DMSH) was proposed for zirconium determination individually and simultaneously with vanadium without separation (Varghese and George 2012). Zirconium forms a complex of $1: 2$ with this reagent, and the competing reaction proceeds with vanadium. The spectra of the complexes and their derivatives overlap; to eliminate the vanadium effect, a "zero-crossing" method was used (as in El-Sayed, Hamed \& El-Reefy, 2010) (the analytic zirconium signal was fixed not at the peak of the complex absorption band but at $405 \mathrm{~nm}$ ). The technique was successfully tested on samples of ilmenite (titanic iron ore) and steels: $0.2-1 \mathrm{wt} . \%$ of zirconium was determined in the presence of iron, cobalt, nickel, and titanium in the amount of tens of percent without any separation.

Uysal, Huseyinli, and Güray (2011) synthesized another new reagent, 2,2',3,4-tetrahydroxy-3'-sulpho-5'carboxyazobenzene (tetrahydroxyazone SC), forming a 2:1 complex with zirconium. It is shown that the reagent has an advantage over arsenazo III; namely, the sensitivity is higher, and influence from many ions is less, especially from cobalt, chromium, nickel, aluminum, zinc, uranium. In addition, the high selectivity of reaction makes possible the zirconium content determination in aluminum and copper alloys without separation. The determination procedure is fast and simple.

An unusual photometric reagent forming with zirconium a complex of yellow color is proposed. It is the acid extract of the leaves of platanus tree. The reaction is selective; however, the molar absorption coefficient of this complex is $5.9 \cdot 10^{3} \mathrm{l} \cdot \mathrm{mol}^{-1} \cdot \mathrm{cm}^{-1}$, which is not very high. But the advantage of this technique is its ecological compatibility, no need to use toxic solvents (Monji, Zolfonoun \& Ahmadi, 2008).

The extraction concentrating was carried out in Gidwani et al. (2009). The authors synthesized calixarene- $N, N^{\prime}$-(3-carboxycoumarin)-7,19-dinitro-25,26,27,28-tetrahydroxy-1,13-calix[4]aryl-hydroxamic acid (CCHA). The reagent was used for extracting zirconium from the analyzed solution (in $0.5 \mathrm{~m} \mathrm{HCl}$ medium, selective extraction of titanium in 6-8 $\mathrm{M} \mathrm{HCl}$ ) and its subsequent determination in the samples of lead-zirconiumtitanium piezoelectrics and environmental objects in the form of a triple complex $\mathrm{Zr}$-CHHA-Morin. The reaction is highly selective.

It was proposed in Bagda and Tuzen (2015) to extract the complex of reagent 2-(5-bromo-2-pyridylaso)-5(diethylamino)-phenol with zirconium using the ionic liquid, 1-hexyl-3-methylimidazolium hexafluoro phosphate, in the presence of a surfactant Triton X-114. This technique was used for determining zirconium in water, dental materials, and artificial saliva. The authors achieved a relatively low detection limit of $0.012 \mu \mathrm{g} \cdot \mathrm{l}^{-1}$, but many ions interfered with the determination already in small excess (nickel (II), copper (II), Fe (III), and F - at 2-fold excess).

Some authors proposed to concentrate zirconium from solutions on a Sephadex LX-20 dextran gel as a complex with 2-(2-benzothiazolylazo)-3-hydroxyphenol (BTAHP) (Amin 2014). The technique is characterized by a rather low detection limit of up to $0.08 \mu \mathrm{g} \cdot \mathrm{l}^{-1}$, while a high mass excess of foreign ions does not interfere: alkaline and alkaline earth elements - 2500-6000-fold (excluding cesium-300-fold); transition metals - 250-1250fold; and rare-earth - 200-fold. The technique was used to analyze various types of surface water, wastewater and tap water, ore samples, soil, and plant materials.

The state-of-the-art procedure for zirconium determination is described in Pecev et al. (2007), namely, the kinetic method based on the oxidation of 4-hydroxycoumarin with potassium permanganate. Zirconium (IV) catalyzes this reaction; calibration plots - the dependence of difference in the optical density of $\mathrm{KMnO}_{4}$ in the absence or presence of zirconium in the solution on its concentration - are linear for zirconium content in the solution for $0.1-1.25 \mathrm{mg} \cdot \mathrm{l}^{-1}$. The reached detection limit was $0.04 \mathrm{mg} \cdot \mathrm{l}^{-1}$.

The article by Himeno, Kitano, and Chaen (2007) describes another spectrophotometric procedure for the zirconium determination with a preliminary separation of zirconium and hafnium by capillary electrophoresis. In this work, zirconium was determined simultaneously with hafnium in the form of complex with an ion $\left[\mathrm{PW}_{11} \mathrm{O}_{39}\right]^{7-}$. The stable anion $\left[\mathrm{P}\left(\mathrm{Zr}^{\mathrm{IV}} \mathrm{W}_{11}\right) \mathrm{O}_{40}\right]^{5-}$ was separated from $\left[\mathrm{P}\left(\mathrm{Hf}^{\mathrm{IV}} \mathrm{W}_{11}\right) \mathrm{O}_{40}\right]^{5-}$ in a capillary from the calcined silicon dioxide filled with $0.15 \mathrm{~m}$ chloroacetate buffer (separation of peaks of two ions with the same electrophoretic mobility was only possible with it). The sample solution was introduced into the capillary from the cathode side. Two separate peaks on the electrophoretogram were detected spectrophotometrically at 258 $\mathrm{nm}$. The range of zirconium determination is $5 \cdot 0 \cdot 10^{-7}-1 \cdot 0 \cdot 10^{-5} \mathrm{~mol} \cdot \mathrm{l}^{-1}$. The detection limit is $2 \cdot 10^{-7} \mathrm{~mol} \cdot \mathrm{l}^{-1}(18$ $\left.\mu \mathrm{g} \cdot \mathrm{l}^{-1}\right)$. The technique was used for zirconium determination in natural water samples. The other components that also form complexes with $\left[\mathrm{PW}_{11} \mathrm{O}_{39}\right]^{7-}$, such as titanium and trivalent ions ( $\mathrm{Sb}$ (III), $\mathrm{Al}$ (III), Ga (III), In (III), Fe (III), Cr (III), Bi (III), Sc (III), Y (III), and La (III)), do not interfere.

Immobilization of photometric reagents on the surface of sorbents and application of the obtained sorbents for analysis of investigated solutions with the use of diffuse reflectance spectra have recently become popular. In Dedkova, Shvoeva, and Savvin (2013, 2014) , and Shvoeva, Dedkova, and Savvin (2012), inexpensive commercially available polyacrylonitrile fiber materials filled with ion exchange resins are used for the sorption- 
spectroscopic determination of zirconium. The materials are stable in the range from strongly acidic to a slightly alkaline medium. The fibrous sorbent was used for zirconium determination (filler-PANV-KU-2) as follows: the sorbent disk was kept in the analyzed solution, then treated with diphenylguanidine chloride, arsenazo III solution and 7-10 M nitric acid; after that, a diffuse reflection signal $\left(\mathrm{R}_{660(670)}\right)$ was measured. At the same time, chromium separation on the disk with another ion-exchange filler is possible, if necessary; nickel is determined on the same disc, but using dimethylglyoxime and in an alkaline medium. A variant of this technique with the flow cell is also possible. The procedures were used to analyze synthetic mixtures with the zirconium content of 5-50 $\mu \mathrm{g} \cdot 1^{-1}$. The detection limit was $2 \mu \mathrm{g} \cdot 1^{-1}$, and significant excess of metals - 2000-fold Cr (VI), Zn (II), and Co (II); 3000-fold Mo (VI); 5000-fold V (V); and 10,000-fold Cu (II) - do not interfere with the determination.

In recent years, a modern method of molecular spectroscopy, Laser Ablation Molecular Isotopic Spectrometry (LAMIS), has become widely used in practice to determine the isotope ratio of zirconium. LAMIS is a method for rapid isotope analysis that examines the optical spectra of molecules formed in plasma produced by a laser when the material is irradiated in air or in a gaseous medium. Molecules are formed during plasma cooling from the atomized substance and the components of surrounding atmosphere. Different isotopes of the same element produce the electronically, vibrationally, and rotationally excited isotopologues of dimers, oxides, nitrides, or halides, whose spectra are different from each other. LAMIS allows performing the distant analysis of a sample (a few meters away). Bol'shakov et al. (2016) give examples of determining the ratio ${ }^{90} \mathrm{Zr} /{ }^{91} \mathrm{Zr} /{ }^{92} \mathrm{Zr} /{ }^{94} \mathrm{Zr}$ in metallic zirconium and zirconium oxide with LAMIS on the molecular emission of $\mathrm{ZrO}$.

\section{Methods of atomic spectroscopy}

Table 4 presents some quantitative data on the zirconium content in various objects obtained by atomic optical spectroscopy as well as information on the currently valid standard documentation.

Table 4: Determination of zirconium by atomic spectroscopy.

\begin{tabular}{|c|c|c|c|c|}
\hline Analysis method & Object & $\lambda, \mathrm{nm}$ & Determined contents & References \\
\hline \multirow[t]{6}{*}{$\begin{array}{l}\text { Atomic absorption, with } \\
\text { atomization in the flame } \\
\text { acetylene - nitrous oxide }\end{array}$} & Antiperspirants & 360.12 & $\begin{array}{l}2.5-7.5 \mathrm{wt} . \% \\
\left(100-500 \mathrm{mg} \cdot \mathrm{l}^{-1}\right)\end{array}$ & $\begin{array}{l}\text { Fifth Commission } \\
\text { Directive } \\
\text { 93/73/EEC } 1999\end{array}$ \\
\hline & $\begin{array}{l}\text { Drinking water, } \\
\text { wastewater, soil }\end{array}$ & & $\begin{array}{l}0.15-0.8 \mathrm{mg} \cdot \mathrm{l}^{-1} \text { (after } \\
\text { preconcentration) }\end{array}$ & Afzali et al. 2014 \\
\hline & Zircon (including as a & & Up to 88 wt. $\%$ & Yadav, Bhowmik \\
\hline & stabilizing additive to solid & & $18-36$ wt. $\%$ (up to 10 & \& Sikder, 2012 \\
\hline & rocket fuel) & & $\mathrm{mg} \cdot \mathrm{l}^{-1}$ after & Shokrollahi and \\
\hline & Glass and refractory bricks & & preconcentration) & Gohari 2017 \\
\hline \multirow{5}{*}{$\begin{array}{l}\text { Atomic emission with arc } \\
\text { excitation } \\
\text { Inductively coupled } \\
\text { plasma atomic emission } \\
\text { (AES-ICP) }\end{array}$} & Boron carbide & 339.19 & $7 \cdot 10^{-5}-4.5 \cdot 10^{-4}$ wt. $\%$ & $\begin{array}{l}\text { Amberger et al. } \\
2011\end{array}$ \\
\hline & Nickel alloys & 343.82 & $0.001-0.1$ wt. $\%$ & $\begin{array}{l}\text { Romanova et al. } \\
2012\end{array}$ \\
\hline & Geochemical solutions & $\begin{array}{l}327.3 \\
349.62\end{array}$ & $0.03-20 \mathrm{mg} \cdot 1^{-1}$ & $\begin{array}{l}\text { Sedykh, } \\
\text { Starshinova \& } \\
\text { Medvedeva, } 2013\end{array}$ \\
\hline & Copper alloys & 343.823 & $0.02-0.05$ wt. $\%$ & $\begin{array}{l}\text { Jayalatha et al. } \\
2012\end{array}$ \\
\hline & Silicone & $\begin{array}{l}327.305 \\
343.823 \\
349.621\end{array}$ & $0.0004-0.0018$ wt. $\%$ & $\begin{array}{l}\text { Rietig and Acker } \\
2017\end{array}$ \\
\hline \multirow{2}{*}{$\begin{array}{l}\text { AES-ICP with cloud } \\
\text { point extraction of } \\
\text { analyte }\end{array}$} & $\begin{array}{l}\text { Surface water, drinking } \\
\text { water }\end{array}$ & 343.823 & $0.0005-1.5 \mathrm{mg} \cdot \mathrm{l}^{-1}$ & $\begin{array}{l}\text { Shariati, Yamini \& } \\
\text { Zanjani, } 2008\end{array}$ \\
\hline & $\begin{array}{l}\text { Surface water, drinking } \\
\text { water, rocks, silver alloy }\end{array}$ & 343.82 & $0.0005-1 \mathrm{mg} \cdot \mathrm{l}^{-1}$ & $\begin{array}{l}\text { Mortada, Ali \& } \\
\text { Hassanien, } 2013\end{array}$ \\
\hline \multirow[t]{3}{*}{$\begin{array}{l}\text { AES-ICP with extraction } \\
\text { of analyte in solid phase }\end{array}$} & River water, tap water & - & $0.05-9 \mathrm{mg} \cdot \mathrm{l}^{-1}$ & $\begin{array}{l}\text { Faghihian and } \\
\text { Kabiri-Tadi } 2010\end{array}$ \\
\hline & $\begin{array}{l}\text { Tap water, surface water, } \\
\text { copper alloy, soil }\end{array}$ & 343.82 & $\begin{array}{l}0.005-0.1 \mathrm{mg} \cdot \mathrm{l}^{-1} \\
\text { (flow-injection version) }\end{array}$ & Karami et al. 2006 \\
\hline & $\begin{array}{l}\text { Wastewater, tap water, } \\
\mathrm{Cu}-\mathrm{Co} \text { alloy }\end{array}$ & 339.1 & $0.00025-0.3 \mathrm{mg} \cdot \mathrm{l}^{-1}$ & Chang et al. 2008 \\
\hline
\end{tabular}




\begin{tabular}{llccc}
$\begin{array}{l}\text { AES-ICP with extraction } \\
\text { of the matrix }\end{array}$ & Solutions of leaching & 349.62 & $0.01-0.5 \mathrm{mg} \cdot \mathbf{1}^{-1}$ & Ayranov et al. 2009 \\
$\begin{array}{l}\text { AES-ICP with laser } \\
\text { ablation }\end{array}$ & Glass & 343.82 & $0.0019-0.0269$ wt.\% & $\begin{array}{l}\text { Schenk and } \\
\text { Almirall 2012 }\end{array}$ \\
$\begin{array}{l}\text { AES-ICP with } \\
\text { electrothermal } \\
\text { evaporation }\end{array}$ & Boron nitride & 257.14 & $0.00004-0.00023$ wt.\% & Barth et al. 2007 \\
LIBS & Magnesium alloys & 349.62 & $0.1-0.8$ wt. $\%$ & Xin et al. 2016 \\
\hline
\end{tabular}

Flame atomic absorption spectroscopy is not often used for determining zirconium due to the high stability of its compounds and their poor atomization in the flame. The best detection limit for zirconium in hightemperature $\mathrm{C}_{2} \mathrm{H}_{2}-\mathrm{N}_{2} \mathrm{O}$ flame is rather high $\left(450 \mu \mathrm{g} \cdot \mathrm{l}^{-1}\right)$ (Pupyshev 2009). It is not recommended to determine zirconium by the electrothermal atomization method because heat-resistant carbides and oxides of zirconium are formed in the graphite furnace (Burylin et al. 2011). The most sensitive analytical line for zirconium is at $360.12 \mathrm{~nm}$, and this line is used in a few methods presented in Table 4 (Fifth Commission Directive 93/73/EEC, 1999; Yadav, Bhowmik \& Sikder, 2012; Afzali et al., 2014; Shokrollahi \& Gohari, 2017). To reduce the detection limit of zirconium to $44 \mu \mathrm{g} \cdot 1^{-1}$, Afzali et al. (2014) used the preliminary microextraction of analyte as a ternary complex with fluoride ions and the 2-(5-bromo-2-pyridylazo)-5-diethylaminophenol (5-Br-PADAP).

Atomic emission is more often used in modern analytical practice of determining zirconium. The popularity of this method is due to a lower detection limit (a typically determined mass content is from 0.0002 to $3 \mathrm{wt}$ \%). Atomic emission spectroscopy that excites atoms and ions with inductively coupled plasma (AES-ICP) is the mostly preferred method in this field nowadays. AES-ICP techniques are the most reproducible; the detection limits of zirconium, indicated by different manufacturers of spectrometers for AES-ICP in solution, are in the range $0.5-5 \mu \mathrm{g} \cdot \mathrm{l}^{-1}$ (in particular, according to the site http:/ / www.perkinelmer.com) $\left((0.2-2) \cdot 10^{-4} \mathrm{wt} . \%\right)$.

The development of atomic emission techniques for zirconium determination (Amberger et al., 2011; Jayalatha et al., 2012; Romanova et al., 2012; Sedykh, Starshinova \& Medvedeva, 2013; Pechishcheva et al., 2017; Rietig \& Acker, 2017) usually includes the investigation of a number of procedures to eliminate the influence of sample composition on the analytical signal and to improve the metrological characteristics. These procedures are the choice of sample pretreatment and separation technique for interfering elements, the choice of analytic line free from overlapping lines of accompanying components and with a sufficient signal-to-noise ratio, the optimization of operating conditions, the calibration method for spectrometer, the method of introducing the sample into the source of spectrum excitation, and so on.

Cloud point extraction with a nonionic surfactant (Triton X-114) and the complexing agent dibenzoylmethane was applied in Shariati, Yamini, and Zanjani (2008), the detection limit was $0.20 \mu \mathrm{g} \cdot 1^{-1}$, and hafnium, thorium, and uranium were also concentrated. The cloud point extraction of zirconium complex with alizarin red S in mixed micelles of Triton X-114 and ammonium cetyltrimethyl ammonium bromide was described in Mortada, Ali, and Hassanien (2013). The application of ammonium sulfate as a salting out agent allowed the authors to carry out extraction at room temperature (usually the required temperature is about $50^{\circ} \mathrm{C}$; Shariati, Yamini \& Zanjani, 2008). The metrological characteristics of that procedure are similar to the two mentioned above: a detection limit of $0.18 \mu \mathrm{g} \cdot \mathrm{l}^{-1}$, with hafnium being concentrated simultaneously.

Several papers under review deal with developing techniques for concentrating zirconium on a solid sorbent (Karami et al., 2006; Chang et al., 2008; Faghihian \& Kabiri-Tadi, 2010). The detection limit of zirconium in waters and alloy is $0.14 \mu \mathrm{g} \cdot \mathrm{l}^{-1}$ (lower than in the papers about cloud point extraction), according to Chang et al. (2008). These authors used the molecular imprinting method in order to synthesize a polymeric sorbent based on silica gel functionalized with amino groups. They synthesized the polymeric sorbent in the presence of zirconium salt solution and then removed the metal ions by washing in the solution of hydrochloric acid. Although this developed technique for determining zirconium is a multistage procedure, it is characterized by a sufficiently low relative standard deviation $\left(1.49 \%\right.$ for the eight results of analysis at the level of $\left.1 \mu \mathrm{g} \cdot \mathrm{l}^{-1}\right)$.

The work of Faghihian and Kabiri-Tadi (2010) describes the application of a cheap natural sorbent, zeolite, modified with a cationic surfactant and a PAN (1-(2-pyridylazo)-2-naphthol) for concentrating zirconium. After passing the zirconium containing solution through the column filled with the reagent, the analyte was eluted with $2 \mathrm{~m} \mathrm{HCl}$. The maximum detection limit was $0.1 \mu \mathrm{g} \cdot \mathrm{l}^{-1}$.

A flow injection solid phase extraction was proposed for determining zirconium along with hafnium in waters, soil, and copper alloy (Karami et al. 2006). The sorbent was octadecylsilica gel modified with quinalizarin. The authors proposed an original flow-injection scheme, where the mixture of $3 \mathrm{~m}$ hydrochloric acid and $0.5 \mathrm{~m}$ nitric acid was used as the carrier phase and eluent. The detection limit was $0.04 \mu \mathrm{g} \cdot 1^{-1}$.

In Ayranov et al. (2009), the interfering matrix component was extracted from hydrogeological solutions under study. After removing iron by diethyl ether, the authors determined 10 microcomponents, including zirconium, in the aqueous phase. It was possible to reach the detection limit of $0.8 \mu \mathrm{g} \cdot 1^{-1}$. 
Laser ablation was used in AES-ICP determination of zirconium (with another eight components) in glass (Schenk and Almirall 2012), the technique was developed for forensic science. Under optimal ablation conditions, a detection limit of $7 \cdot 10^{-4} \mathrm{wt} . \%$ was achieved for zirconium. It is shown that the method is not inferior in accuracy and reproducibility to more expensive MS with laser ablation. Another variant of AES-ICP that does not imply the transfer of sample into a solution was proposed in Barth et al. (2007). Electrothermal evaporation, used in this study for zirconium determination in boron nitride, significantly shortened the analysis time and yielded record values of the detection limit of $4 \cdot 1 \cdot 10^{-6} \mathrm{wt} . \%$, although the relative standard deviation value of $11 \%$ was significantly high for 228 measurements of zirconium at the level of $0.00005 \mathrm{wt} . \%$.

A relatively new method of atomic spectroscopy, laser-induced breakdown spectroscopy (LIBS) in its double-pulse variant (for increasing the sensitivity of determination), was tested in Xin et al. (2016) for zirconium determination in a new type of magnesium alloys. The distance from the laser to the sample was 1.89 $\mathrm{m}$. The detection limit of zirconium of this method was quite high, $0.09 \mathrm{wt} . \%$.

\section{X-ray fluorescence analysis}

X-ray fluorescent (XRF) techniques for zirconium determination together with a large number of other analytes are presented, for example in the works of Viswanathan et al. (2013) and Cherkashina et al. (2009), where the sample preparation of the dispersed analyte is made by pressing, which provides a rapid analysis. For carrying out XRF, the samples are also fused with alkali metal borates to produce glass disks; sometimes polished disks of metals and alloys are used, and occasionally, solutions. The current popularity of this method is accounted for by the development of software that allows recording multiple effects of sample components on the analytical signal.

Some works published in recent years concern the determination of microquantities of zirconium by X-ray diffraction method in rocks (Krishna, Khanna \& Mohan, 2016; Viswanathan et al., 2013), soil (Bowen, 1979; Krishna, Khanna \& Mohan, 2016), minerals (Cherkashina et al. 2009), and porcelain (Ichikawa, Matsumoto \& Nakamura, 2016). The main content of these studies is the choice of calibration samples or their production technique, optimal conditions for spectrum excitation, the background correction, and consideration of mutual influences of components due to both spectral overlapping and reabsorption of XRF. Under optimal conditions, the detection limit of zirconium is about $4 \cdot 10^{-4} \mathrm{wt} . \%$.

Recently, the XRF analysis with spectrum excitation by a 2-3 MeV proton beam has become rather widespread. It is referred to as proton-induced X-ray emission (PIXE) technique. The advantage of this modification of XRF is the ability to analyze samples of different size without any preparation, dilution, or evacuation of the sample. The work of Garcia et al. (2012) describes the determinations of zirconium at the level of 15-25 wt.\% (with six macrocomponents and microcomponents simultaneously) in piezoceramic samples. The author focuses on the evaluation of reproducibility of measurements and accuracy monitoring for the analysis results, since there are no suitable standard ceramic samples with certified content of the target analytes. In comparison with ISP-AES, the results of zirconium content determination by the PIXE method were obtained lower than the required with a smaller relative standard deviation $(1 \%)$, but the results of both methods are within the error limits, so this method is considered suitable for controlling the process of ceramics production, in particular for sample homogeneity.

There is another modern modification of the XRF analysis. It is the total external reflection XRF that is used for the analysis of catalysts consisting of zirconium compounds immobilized on quartz microspheres (Fernandez-Ruiz et al. 2010). This method is successfully used for the analysis of small amounts of liquid or solid samples placed on a flat quartz plate (Alov 2010). Primary radiation falling on a sample at a sliding angle of about $\left(0.1^{\circ}\right)$ is used to excite $X$-rays. The method allows obtaining higher signal-to-noise ratios and achieving lower detection limits than with XRF in standard implementation. By the TXRF method, zirconium was determined directly in the catalyst powder (weight $5 \mu \mathrm{g}$ ) and in its acid leach solution (Fernandez-Ruiz et al. 2010). It is shown that the TXRF signal for powder samples depends on the average size of their particles. When it is less than $1 \mu \mathrm{m}$, the results for powder samples and leaching solutions match, as well as the minimum detection limit (376 pg of zirconium) and the minimum random error of determination $(0.3 \%$ rel.). The samples were also analyzed by inductively coupled plasma (ICP)-MS, and a satisfactory match of the results was obtained.

\section{Inductively coupled plasma mass spectrometry}

ICP-MS is generally applied to the determination of zirconium simultaneously with other components, mainly in microquantities. It is commonly used in geological, ecological, and criminological analysis. According to 
the standards for analytical methods, the determination of zirconium is controlled in soil, silt, and recycled biological waste (ISO/TS 16965:2013 2013), glass samples for forensic examination (ASTM E2330-12 2012).

Zirconium concentration is determined mainly by its stable isotopes ${ }^{90} \mathrm{Zr}$ or ${ }^{91} \mathrm{Zr}$ (the first of which is the most common; the isotopes ${ }^{92} \mathrm{Zr}$ and ${ }^{94} \mathrm{Zr}$ are also stable) in the studies of radioactive contamination - by the radionuclides ${ }^{93} \mathrm{Zr}$ or ${ }^{96} \mathrm{Zr}$. To increase accuracy, internal standardization is applied, with the use of, for example, ${ }^{115} \mathrm{In},{ }^{7} \mathrm{Li},{ }^{205} \mathrm{Tl}$, and ${ }^{103} \mathrm{Rh}$ (Nagaishi \& Ishikawa, 2009; Kon et al., 2011; Azcarate et al., 2015; Bolea-Fernandez et al., 2016).

In many works on the MS determination of zirconium, the main focus is on the development of a sample preparation procedure (in particular, preconcentration), the separation of interfering matrix components, and techniques for introducing samples into inductively coupled plasma.

The works describe, for example, the ICP-MS determination of zirconium in a number of oceanographic tracers - indicator elements that allow monitoring the mass movement of seawater and the pollution extent in it. However, determination of trace element concentration in saline waters by the ICP-MS method is a problem due to the fact that salt matrix has a significant spectral effect on the determination results (the overlapping of zirconium signal and the signal from polyatomic ions, for example ${ }^{40} \mathrm{Ar}^{35} \mathrm{C}^{118} \mathrm{O}$ and ${ }^{40} \mathrm{Ar}^{37} \mathrm{C}^{116} \mathrm{O}$ ), as well as the nonspectral effect associated with blocking of the MS spray system. In Raso, Censi, and Saiano (2013), coprecipitation on iron hydroxide was carried out in order to remove trace impurities, including zirconium, from the salt matrix and, simultaneously, to provide concentration. The detection limit of zirconium is 0.061 $\mu \mathrm{g} \cdot \mathrm{l}^{-1}$. Firdaus et al. (2007) applied a polymeric resin modified with 8-hydroxyquinoline to separate the target analytes from the salt matrix and concentrate them. Sample preparation was performed offline, although a closed system was used for preconcentration, which decreases the risk of contamination significantly. The stationary phase for solid-phase extraction, TSQ-8HQ, was synthesized manually. After sorption, the column with sorbent was washed with 5 м HF, then zirconium concentration was determined in the obtained solution at the level of $10-30 \mathrm{ng} \cdot \mathrm{l}^{-1}$; the detection limit was $0.015 \mathrm{ng} \cdot \mathrm{l}^{-1}$. In Sun and $\mathrm{Li}$ (2015), the authors used an ion exchange resin containing $\mathrm{N}$-benzoyl- $\mathrm{N}$-phenylhydroxylamine (BPHA) to separate the zirconium (alongside with $\mathrm{Nb}, \mathrm{Mo}, \mathrm{Sn}, \mathrm{Hf}, \mathrm{Ta}$, and $\mathrm{W}$ ) from the matrix and interfering components of seawater. After washing the solution with $1 \mathrm{~m} \mathrm{HCl}$ for removing $\mathrm{Fe}, \mathrm{Mn}, \mathrm{Cu}$, Zn, etc., and with $1 \mathrm{~m} \mathrm{HCl} / 0.4 \% \mathrm{H}_{2} \mathrm{O}_{2}$ solution for the elution of Ti, the investigated analytes were eluted with a $6 \mathrm{~m} \mathrm{HF} / 1 \mathrm{~m} \mathrm{HCl}$ mixture. In the obtained solution, the zirconium concentration was determined at the level of $0.5-3 \mathrm{ng} \cdot \mathrm{l}^{-1}$; the detection limit was $0.05 \mathrm{ng} \cdot \mathrm{l}^{-1}$. In Poehle, Schmidt, and Koschinsky (2015), a fast technique for zirconium determination in seawater by adapting the online-preconcentration procedure with the commercially available SeaFAST system (Elemental Scientific) and subsequent analysis by ICP-MS to this metal was presented. The prepacked preconcentration column contained a chelating resin with two functional groups, ethylenediamine triacetic acid and iminodiacetic acid, immobilized on a polymer backbone. Titanium, $\mathrm{Zr}, \mathrm{Nb}$, and $\mathrm{W}$ were measured simultaneously in one run. Very good spike recoveries achieved with spiked North Seawater demonstrate the applicability for all elements. Due to the limit of detection (LOD) of about $1 \mathrm{ng} \cdot 1^{-1}$, this method enables the determination of $10-50 \mathrm{ng} \cdot 1^{-1} \mathrm{for} \mathrm{Zr}$. The required sample volume of only $50 \mathrm{ml}$, the fast determination within 1 hour, and the principle of a closed system are clear advantages of the analytical procedure.

The concentration of zirconium by sorption with a resin containing TOGDA $\left(N, N, N^{\prime}, N^{\prime}\right.$-tetraoctyl-1,5diglycolamide) from solutions simulating high-salt groundwater was studied in Gautier et al. (2013), while developing a control procedure for pollution caused by ${ }^{93} \mathrm{Zr}$ leaking from radioactive waste tanks. The detection limit was $0.03 \mu \mathrm{g} \cdot 1^{-1}$.

The AG 50Wx8 cation exchange resin was successfully used in Tindemans et al. (2014): after acid dissolution of high-alloy steel samples and the separation of matrix ( $\mathrm{Ni}, \mathrm{Cr}$, Fe, etc.) on cation exchange resin, the zirconium content was determined as $0.009-0.206 \mathrm{wt} . \%$ along with a large number of other alloying and impurity components.

The development of fusion procedure for the analysis of geological reference samples was the focus in Park et al. (2012). Minerals containing zirconium (zircon, in particular) are usually difficult to decompose by mixtures of acids in open vessels, even containing hydrofluoric acid (Nagaishi and Ishikawa 2009), and alkaline fusion leads to high dilution of the samples and, consequently, to increasing detection limit. Park et al. (2012), using the original sample preparation procedure (fusing with flux, remelting and milling the obtained discs, and dissolving the glass powder in a small quantity of acids), achieved the reproduction of certified zirconium values in the range of $0.015-0.065 \mathrm{wt} . \%$ in standard samples. The limit of detection of zirconium was 0.87 $\mu \mathrm{g} \cdot \mathrm{l}^{-1}$.

The work of Bayon et al. (2009) deals with the determination of zirconium and a number of other elements in samples of various types of rocks, sediments, and soils. Sample preparation was carried out by fusion. Zirconium was determined in the range $0.0005-0.08 \mathrm{wt} . \%$; the detection limit was $1.7 \cdot 10^{-7} \mathrm{wt} . \%$ The use of crucibles from glassy carbon instead of usual crucible material allowed the solution contamination to be reduced during 
fusion for ICP-MS analysis. The interfering effect of matrix components was eliminated by coprecipitation of analytes on iron (III) hydroxide.

Bao et al. (2016) proposed a sample preparation technique for silicate ores with zircon. The technique was used for the ICP-MS analysis. It involves rapid fusion of a sample in a vessel of boron nitride without flux, followed by its dissolution in screw-top Teflon vials in a mixture of $\mathrm{HF} / \mathrm{HNO}_{3}$ on the oven for $6 \mathrm{~h}$ at $150^{\circ} \mathrm{C}$. The results of zirconium determination (at a level of $0.01-0.05 \mathrm{wt} . \%$ ) had satisfactory precision (RSD $\leq 4 \%$ ) and accuracy (relative error $\leq 10 \%$ ) for almost all the 10 test samples.

The complete decomposition technique of bauxite samples for the determination of zirconium and other 36 microimpurities by ICP-MS is described in Zhang et al. (2015). It includes $\mathrm{NH}_{4} \mathrm{HF}_{2}$ or $\mathrm{NH}_{4} \mathrm{~F}$ open vessel digestion, followed by the precipitate treatment with perchloric acid. Thus, the developed procedure allowed zirconium determination at the level of $0.04-0.26 \mathrm{wt} . \%$ in standard samples with RSD no more than $5.5 \%$ and a detection limit of the order of $1 \cdot 10^{-8}$ wt.\%.

The work of Kon et al. (2011) describes the development of a technique for analyzing glass samples obtained by fusing the material under research with lithium tetraborate and designed for calibrating XRF spectrometers used to determine the composition of geological materials. The sample was introduced into the MS plasma by femtosecond laser ablation. The zirconium content in the ${ }^{90} \mathrm{Zr}$ isotope was determined in 12 standard reference materials at the concentration range $0.005-0.015 \mathrm{wt} . \%$. The error (deviation from the mean and RSD) of the obtained analysis results was within $10 \%$ relative.

A femtosecond laser has also been used for in situ analysis of quartz inclusions (Borisova et al. 2008). Such analysis helps to obtain important information on the origin of rocks. Zirconium was determined in the range of $0.012-0.046 \mathrm{wt}$. \% among 34 microcomponents. The detection limit of $6 \cdot 10^{-6} \mathrm{wt} . \%$ reached is lower than that obtained with the use of a nanosecond laser. It is also shown that the technique allows obtaining a more intense signal from a restricted analysis zone of $60 \mu \mathrm{m}$, and it is a great advantage for the analysis of inclusions.

In Petrelli et al. (2007), the authors proposed an interesting sample preparation procedure suitable for the analysis of small amounts (the order of $50 \mathrm{mg}$ ) of geological samples by the ICP-MS method with laser ablation. The sample is fused with lithium tetraborate in the crater of a graphite electrode. As a result, small (about $5 \mathrm{~mm}$ diameter) glass discs are obtained and used for analysis. When determining the zirconium concentration (and many other elements) in the standard reference materials (in the range of $0.018-0.076 \mathrm{wt} . \%$ ), the characteristics of random and systematic error of analysis results were within $10 \%$ relative, the detection limit was $4.10^{-6} \mathrm{wt} . \%$ Another example of using ICP-MS with laser ablation is found in Duodu et al. (2015). The authors proposed a procedure for sample preparation of sediment (marine, stream, and drainage) by milling in ethanol for 40 min in a disk mill. It has been shown that $90 \%$ of analyzed material particles are of a size less than $6 \mu \mathrm{m}$, and the sample is easily compressed into a pellet by manual press without a binder for laser ablation. As a result, high homogeneity of a material is achieved, which leads to improvement in the precision of analysis. The cohesiveness of the pressed pellet samples give a much more stable transient signal during ablation. Small particles are easier to introduce into the ICP-MS plasma torch and they are more easily degraded there. Finally, the recovery and detection limit are improved (for zirconium, 3.1·10 $\left.{ }^{-7} \mathrm{wt} . \%\right)$. Thus, zirconium can be identified along with most of matrix elements and impurities, volatile included, making use of a single procedure and without application of toxic reagents for sample preparation.

In coal, zirconium was determined along with 15 other trace elements after microwave preparation. Sample preparation parameters such as temperature, extraction time, $\mathrm{HNO}_{3}$, and $\mathrm{H}_{2} \mathrm{O}_{2}$ concentrations were optimized. The precision of the proposed technique, expressed in terms of RSD ( $n=15)$, was 3\% (Mketo, Nomngongo \& Ngila, 2015).

The multicollector ICP-MS (MC-ICP-MS), in combination with the isotopic dilution technique, was used for determination of ${ }^{93} \mathrm{Zr}$ radionuclide with high accuracy in the irradiated zirconium alloy in fuel shells of reactors (Chartier et al. 2008). Zirconium was preliminarily separated from matrix components of the alloy, in particular, molybdenum and niobium, and other radionuclides by selective methods of chemical separation, including extraction of its complex and ion exchange on the AG1X4 resin. The solution, enriched with the ${ }^{96} \mathrm{Zr}$ isotope, was used for isotopic dilution. Also, this method (but with the ${ }^{94} \mathrm{Zr}$ addition) was applied to zirconium determination in glass discs - standard reference materials for MS with laser ablation (Nebel, Marel \& Vroon, 2009). Isotopic dilution with the ${ }^{91} \mathrm{Zr}$ isotope was used in thermal ionization MS procedure developed for zirconium isotope abundance and concentration determination in Quemet, Maillard, and Ruas (2015) for nuclear samples with a high zirconium content. Zirconium was separated, using the UTEVA resin, from the interfering components - molybdenum, niobium, and ruthenium.

Several recent works are devoted to the application of ICP-MS for zirconium determination in biological samples. The work of Azcarate et al. (2015) describes the express milk preparation procedure for the determination of zirconium along with more than 20 elements for milk classification (adult, baby, or baby fortified): solubilization with small amounts of dymethylformamide. For the analysis of obtained solutions, a sample introduction was carried out using a PFA high-efficiency microconcentric nebulizer coupled to a baffled cy- 
clonic spray chamber at $-5^{\circ} \mathrm{C}$ as desolvating temperature. The detection limit of zirconium was $0.76 \mu \mathrm{g} \cdot 1^{-1}$, RSD did not exceed $6 \%$ when determining $20 \mu \mathrm{g} \cdot 1^{-1}$. In Bolea-Fernandez et al. (2016), for the determination of zirconium as one of the prosthesis-related metals, the original sampling procedure - volumetric absorptive micro-sampling (VAMS) - was used in combination with the ICP-MS instrument equipped with a collision reaction cell. VAMS implies the selection of a blood sample directly into the sorbent phase (using devices available under the brand name Mitra- (Phenomenex, USA). Such a sampling device consists of a hydrophilic polymer with an absorption volume of about $10 \mathrm{ml}$. Before the analysis, water elution was carried out. In the MS reaction cell, the methyl fluoride/helium $\left(\mathrm{CH}_{3} \mathrm{~F} / \mathrm{He}-10: 90\right)$ mixture was used as a reaction gas, and as a result of interacting with it, the ${ }^{90,91} \mathrm{ZrF}^{+}$ions formed $(m / z=109,110)$. The use of signal from these ions allowed determining zirconium without matrix interference from the macrocomponents of blood (e.g. C, $\mathrm{Ca}, \mathrm{Cl}, \mathrm{K}, \mathrm{N}, \mathrm{Na}, \mathrm{Mg}, \mathrm{P}$, and S). According to the developed procedure, zirconium was successfully determined at a level of 5-50 $\mu \mathrm{g} \cdot \mathrm{l}^{-1}$; the detection limit was $0.01 \mu \mathrm{g} \cdot \mathrm{l}^{-1}$. At the same time, it was possible to determine the other prosthesis-related metals, $\mathrm{Ti}, \mathrm{V}, \mathrm{Co}$, and $\mathrm{Sr}$.

Recently, a new version of MS, microwave plasma torch (MPT)-MS, was tested for the zirconium determination in water. MPTs can be used as simple and low-power-consumption ambient ion sources. In the work of Yang et al. (2017), MPT was used in combination with a linear ion trap MS. Under the optimized conditions, the LOD was estimated to be at the level $20 \mu \mathrm{g} / 1$ for zirconium, with linear dynamics range 20-200 $\mu \mathrm{g} / \mathrm{l}$. The authors consider MPT-MS to be a promising method, complementing the traditional ICP-MS, because it uses simpler equipment, which can have portable versions, does not require long-term sample preparation, and can be used in the field.

\section{Activation methods}

The activation analysis is another type of multielement chemical analysis used, in particular, for determining zirconium. Neutron activation techniques for zirconium determination are characterized by a relatively high detection limit, because excitation of the most abundant and stable isotope ${ }^{90} \mathrm{Zr}$ by thermal neutron results in the formation of another stable isotope ${ }^{91} \mathrm{Zr}$. For zirconium determination by activation method, the reaction ${ }^{94} \mathrm{Zr}(n, \gamma)^{95} \mathrm{Zr}$ is used fixing the half-life of the formed radioactive isotope and the intensity of emitted gamma radiation. It is also possible to apply the reaction with fast neutrons ${ }^{90} \mathrm{Zr}(n, 2 n){ }^{89,89 \mathrm{~m}} \mathrm{Zr}$ (Elinson and Petrov 1965). The application of neutron activation to determining the components of river sediments for the control of industrial pollution, including zirconium, was reported in Baljinnyam, Frontasyeva, and Aleksiayenak (2014), where activation was carried out by fast, thermal and epithermal neutrons of the nuclear reactor. In Datta, Chowdhury, and Verma (2014), the activation of reactor graphite samples was carried out in order to determine microimpurities and create a standard reference material in two ways: reactor neutrons and a proton beam with the energy of 13-18 MeV. The authors point out the important advantages of proton activation for determining microimpurities: the possibility of analysis without a sample dissolving, a larger capture crosssection, and less effect of matrix activation. Zirconium was determined by the reaction ${ }^{90} \mathrm{Zr}(p, n)^{90} \mathrm{Nb}$; the detection limit was $1 \cdot 10^{-6} \% \mathrm{wt}$. Satisfactory convergence with neutron activation results was achieved. It was concluded that activation by a proton beam is a good alternative to neutron activation analysis without access to neutron sources.

Summarizing the review of methods for determining zirconium, the smallest detection limits of techniques discussed in this paper are presented in Table 5 for comparison.

Table 5: The smallest detection limits of zirconium by the methods considered in this work.

\begin{tabular}{lll}
\hline Method & Detection limit & References \\
\hline Spectrophotometry & Up to $0.012 \mu \mathrm{g} \cdot \mathrm{l}^{-1}$ with preliminary concentration by & $\begin{array}{l}\text { Bagda and Tuzen } \\
\text { ionic liquid }\end{array}$ \\
Sorption spectroscopy method & Up to $2 \mu \mathrm{g} \cdot \mathrm{l}^{-1}$ & $\begin{array}{l}\text { Dedkova, Shvoeva \& } \\
\text { Savvin, 2014 }\end{array}$ \\
& & Schneider et al. 2015 \\
Adsorption voltammetry & Up to $0.4 \cdot 10^{-3} \mu \mathrm{g} \cdot \mathrm{l}^{-1}$ & Afzali et al. 2014 \\
Atomic absorption & Up to $44 \mu \mathrm{g} \cdot \mathrm{l}^{-1} \mathrm{with}$ concentration by microextraction & Karami et al. 2006 \\
Inductively coupled plasma atomic & $0.04 \mu \mathrm{g} \cdot \mathrm{l}^{-1} \mathrm{after}$ solid phase concentration in a & \\
emission & flow-injection version & Barth et al. 2007 \\
& $4.1 \cdot 10^{-6} \mathrm{wt} . \%$ with electrothermal evaporation of solid & \\
XRF analysis & sample & Viswanathan et al.
\end{tabular}


ICP-MS

Activation method
$1.5 \cdot 10^{-3} \mathrm{ng} \cdot \mathrm{l}^{-1}$ after solid phase concentration $1.7 \cdot 10^{-7}$ wt. $\%$

$1 \cdot 10^{-6}$ wt. $\%$
Firdaus et al. 2007

Bayon et al. 2009

Datta, Chowdhury \&

Verma, 2014

It can be seen, in particular, that MS achieves a record detection limit, $1.5 \cdot 10^{-3} \mathrm{ng} \cdot \mathrm{l}^{-1}$ of zirconium after solid phase concentration. However, methods that are relatively simple in instrumentation, such as spectrophotometry with preconcentration and adsorption voltammetry, can achieve typical detection limits for zirconium by the ICP-MS method without additional concentration, as claimed by some manufacturers of analytical equipment $-0.5 \mu \mathrm{g} \cdot \mathrm{l}^{-1}$ (the data from website nytek.ru) and $0.4 \mathrm{ng} \cdot \mathrm{l}^{-1}$ (bruker.com website) - who confirm and demonstrate this.

\section{Conclusion}

The analysis of recent literature data indicates an increased interest of chemical analysts in zirconium, both as an analyte and in terms of application of its compounds for the analysis of different materials. There are various methods for zirconium determination in modern analytical chemistry. Choosing a suitable method, the analyst should be guided by economic considerations, availability of necessary equipment, and characteristics of the objects of analysis.

Classical methods, such as gravimetry and titrimetry, are standardized methods for determining relatively high contents of zirconium. The spectrophotometric and activation methods of determination did not lose their relevance and have been used in the analysis of zirconium for decades. The directions of their improvement deal with the development of instrumentation, the emergence of technologies for mathematical processing of multidimensional analytical signals, and the modernization of sample preparation techniques. Spectrophotometry is also one of the most economical methods for zirconium determination. The use of this method is inadvisable if it is necessary to control simultaneously a wide range of analytes in the samples under study. Nevertheless, under certain conditions, especially with modern concentration techniques, it can compete even with MS in metrological characteristics. The same refers to electrochemical methods for the zirconium determination.

Atomic absorption is not widespread for the zirconium determination due to the complexity of zirconiumcontaining compounds atomization in a flame and graphite tube. As for XRF, it was intensively used recently for determining zirconium along with other components, mainly for the analysis of geological samples.

Since the publications of reviews devoted to the analytical chemistry of zirconium in the second half of the past century, the multielement methods as ICP-AES and ICP-MS with lower detection limit of zirconium have also been widely used, including different variants of introducing solid samples into inductively coupled plasma (with laser ablation, with electrothermal evaporation). For the zirconium determination, some new spectroscopic methods such as LIBS and LIAMS were also tested. Their attractiveness is due to the unnecessary sample preparation and the possibility of remote analysis.

It is noted that analysts give their increased attention to the determination of low zirconium contents in ecological and biological objects. For this purpose, sample preparation schemes are improved, flow-injection schemes are introduced, and some new sorbents and complexing reagents are developed. The use of all these techniques allowed raising the sensitivity of zirconium determination, lowering the detection limit, and increasing the selectivity and the speed of techniques. The best results in almost all of these methods are achieved by the solid-phase extraction, which allows determining zirconium in the presence of a large number of foreign components and simultaneously achieving the smallest detection limits.

It should be noted that the development of methods for zirconium determination is similar to the general trends in modern analytical chemistry. This conclusion follows from a comparison with the techniques where zirconium compounds are used. In general, the development of new express and selective techniques for determining the content of zirconium in a wide range of concentrations in various materials remains an urgent task nowadays. This is due to the fact that existing techniques are not universal, applicable only to certain objects and have a limited range of concentrations. In particular, the task of increasing the speed of determining high zirconium contents using modern methods remains unsolved.

Since the application of zirconium and its compounds is growing in modern fields of science and technology, there is a confidence that the methods of its determination will continue to develop.

\section{Funding}

The study was supported by the Russian Science Foundation under grant no. 14-13-00676. 


\section{References}

Abbaspour, A.; Baramakeh, L. Application of principle component analysis - artificial neural network for simultaneous determination of zirconium and hafnium in real samples. Spectrochim. Acta Part A. 2006a, 64, 477-482.

Abbaspour, A.; Baramakeh, L. Novel zirconium optical sensor based on immobilization of Alizarin Red S on a triacetylcellulose membrane by using principle component analysis artificial neural network. Sens. Actuator B. 2006b, 114, 950-956.

Abdolmohammad-Zadeh, H.; Tavarid, K.; Talleb, Z. Determination of iodate in food, environmental, and biological samples after solidphase extraction with Ni-Al-Zr ternary layered double hydroxide as a nanosorbent. Sci. World ]. 2012, Article ID 145482.

Afzali, D.; Fathirad, F.; Chaseminezhad, S.; Afzali, Z. Determination of trace amounts of zirconium in real samples after microwave digestion and ternary complex dispersive liquid-liquid microextraction. Environ. Monit. Assess. 2014, 186, 3523-3529.

Al-Kady, A. S. Selective and sensitive spectrophotometric method for the determination of trace amounts of zirconium in environmental and biological samples using 4-cloro-N-(2,6-dimethylphenyl)-2-hydroxy-5-sulfamoylbenzamide. Spectrochim. Acta Part A. 2012, 97, 284-289.

Alov, N. V. X-ray fluorescence analysis with total external reflection: physical basis and analytical application. Factory Lab Diagn Mater (Zavodskaya laboratoriya. Diagnostika materialov) 2010, 76, 4-14.

Amberger, M. A.; Barth, P.; Forster, O.; Broekaert, J. A. C. Direct multielement determination of trace elements in boron carbide powders by direct current arc atomic emission spectrometry using a CCD spectrometer. Microchim. Acta. 2011, 172, 261-267.

Amin, A. S. Novel analytical approach for the determination of zirconium using solid phase spectrophotometry. J. Taibah Univ. Sci. 2014, 9 , 227-236.

Arida, H. A. Novel PVC membrane-based thoron ion selective electrode and its application: determination of zirconium. Talanta 2008, 76, $40-43$.

ASTM C545-97 (2013), Standard Classification of Zircon Refractories, ASTM International, West Conshohocken, PA, 2013, www.astm.org.

ASTM C1666/C1666M-08 (2015), Standard Specification for Alkali Resistant (AR) Glass Fiber for GFRC and Fiber-Reinforced Concrete and Cement, ASTM International, West Conshohocken, PA, 2015, www.astm.org.

ASTM D3969-01 (2012), Standard Test Method for Zirconium in Paint Driers by EDTA Method, ASTM International, West Conshohocken, PA, 2012, www.astm.org.

ASTM E2330-12 (2012), Standard Test Method for Determination of Concentrations of Elements in Class Samples Using Inductively Coupled Plasma Mass Spectrometry (ICP-MS) for Forensic Comparisons, ASTM International, West Conshohocken, PA, 2012, www.astm.org.

Ayranov, M.; Cobos, J.; Popa, K.; Rondinella, V. V. Determination of REE, U, Th, Ba, and Zr in simulated hydrogeological leachates by ICP-AES after matrix solvent extraction. J. Rare Earths 2009, 27, 123-127.

Azcarate, S. M.; Savio, M.; Smichowski, P.; Martinez, L. D.; Camina, J. M.; Gil, R. A. Single-step solubilization of milk samples with N,Ndimethylformamide for inductively coupled plasma-mass spectrometry analysis and classification based on their elemental composition. Talanta 2015, 143, 64-70.

Bagda, E.; Tuzen, M. Determination of zirconium in water, dental materials and artificial saliva after surfactant assisted dispersive ionic liquid based microextraction. RSCAdv. 2015, 5, 107872-107879.

Bai, Y.; Dou, Y.; Xie, L.-H.; Rutledge, W.; Li, J.-R.; Zhou, H.-C. Zr-based metal-organic frameworks: design, synthesis, structure, and applications. Chem. Soc. Rev. 2016, 45, 2327-2367.

Baker, T. N. Role of zirconium in microalloyed steels: a review. Mater. Sci. Technol. 2015, 31, 265-294.

Baljinnyam, N.; Frontasyeva, M. V.; Aleksiayenak, Yu.V. INAA for determination of trace elements in bottom sediments of the Selenga River Basin in Mongolia. Phys. Part. Nucl. Lett. 2014, 11, 199-208.

Bao, Z.; Zhang, H.; Yuan, H.; Liu, Y.; Chen, K.; Zong, C. Flux-free fusion technique using a boron nitride vessel and rapid acid digestion for determination of trace elements by ICP-MS. J. Anal. Atom. Spectrom. 2016, 31, 2261-2271.

Barth, P.; Hassler, J.; Kudrik, I.; Krivan, V. Determination of trace impurities in boron nitride by graphite furnace atomic absorption spectrometry and electrothermal vaporization inductively coupled plasma optical emission spectrometry using solid sampling. Spectrochim. Acta, Part B. 2007, 62, 924-932.

Basargin, N. N.; Oskotskaya, E. R.; Simakov, P. E.; Rozovskii, Y. G. Concentration and spectrophotometric determination of zirconium (IV) during the analysis of rock using a chelating sorbent. Inorg. Mater. 2010, 46, 1637-1639.

Bayon, G.; Barrat, J. A.; Etoubleau, J.; Benoit, M.; Bollinger, C.; Révillon, S. Determination of rare earth elements, Sc, Y, Zr, Ba, Hf and Th in geological samples by ICP-MS after Tm addition and alkaline fusion. Ceostand. Ceoanal. Res. 2009, 33, 51-62.

Bobryonok, O. F.; Predtechenskii, M. R. Development of solid-oxide fuel cell for reduced operating temperatures. Russ. J. Electrochem. 2011, 47, $482-487$.

Bolea-Fernandez, E.; Phan, K.; Balcaen, L.; Resano, M.; Vanhaecke, F. Determination of ultra-trace amounts of prosthesis-related metals in whole blood using volumetric absorptive micro-sampling and tandem ICP-mass spectrometry. Anal. Chim. Acta. 2016, 941, 1-9.

Bol'shakov, A. A.; Mao, X.; Conzalez, J. J.; Russo, R. E. Laser ablation molecular isotopic spectroscopy (LAMIS): current state of the art. J. Anal. At. Spectrom. 2016, 31, 119-134.

Borik, M. A.; Bredikhin, S. I.; Bublik, V. T.; Kulebyakin, A. V.; Kuritsyna, I. E.; Lomonova, E. E.; Milovich, P. O.; Myzina, V. A.; Osiko, V. V.; Ryabochkina, P.A.; Tabachkova, N. Y. Structure and conductivity of yttria and scandia-doped zirconia crystals grown by skull melting. J. Am. Ceram. Soc. 2017, 100, 5536-5547.

Borisova, A.; Freydler, R.; Polve, M.; Salvi, S.; Candaudap, F.; Aigouy, T. In situ multi-element analysis of the Mount Pinatubo quartz-hosted melt inclusions by NIR femtosecond laser ablation-inductively coupled plasma-mass spectrometry. Ceostand. Ceoanal. Res. 2008, 32, 209-229.

Bowen, H. Environmental Chemistry of the Elements; Academic Press.: London, 1979; pp 333.

Budziak, D.; Martendal, E.; Carasek, E. Application of robust NiTi-ZrO - -PEC SPME fiber in the determination of haloanisoles in cork stopper samples. Anal. Chim. Acta. 2008, 629, 92-97. 
Burylin, M.Yu.; Zaikovsky, V. I.; Romanovsky, K. A.; Arushanian, P. R. The characteristics of new permanent sorbent-modifiers for the arsenic hydride generation atomic absorption spectrometric determination with trapping of the arsine in a graphite furnace. Analytics and Control. 2011, 15, 23-36.

Cao, D.; Yu, B.; Zhang, S.; Cui, L.; Zhang, J.; Cai, W. Isosorbide production from sorbitol over porous zirconium phosphate catalyst. Appl. Catal.; A. 2016, 528, 59-66.

Castro, M. A.; Aller, A. J.; Faulds, K.; Littlejohn, D. Littlejohn of the effect of nitric acid and metal-based chemical modifiers on graphite platform surfaces by Raman spectrometry. J. Anal. At. Spectrom 2009, 24, 1044-1050.

Chang, X.; Wang, X.; Jiang, N.; He, Q.; Zhai, Y.; Zhu, X.; Hu, Z. Silica gel surface-imprinted solid-phase extraction of Zr(IV) from aqueous solutions. Microchim Acta. 2008, 162, 113-119.

Chang, Y.-J.; Periasamy, A. P.; Chen, S.-M. Poly(Toluidine Blue) and zirconia nanoparticles electrochemically deposited at gelatin-multiwalled carbon nanotube film for amperometric $\mathrm{H}_{2} \mathrm{O}_{2}$ sensor. Int. J. Electrochem. Sci. 2011, 6, 4188-4203.

Chartier, F.; Isnard, H.; Degros, J. P.; Faure, A. L.; Fréchou, C. Application of the isotope dilution technique for ${ }^{93} \mathrm{Zr}$ determination in an irradiated cladding material by multiple collector-inductively coupled plasma mass spectrometry. Int. J. Mass Spectrom. 2008, 270, 127-133.

Cherkashina, T. Yu.; Khudonogova, E. V.; Revenko, A. G.; Letnikova, E. F. Application of the background standard method for the determination of $\mathrm{Rb}, \mathrm{Sr}, \mathrm{Y}, \mathrm{Zr}$, and $\mathrm{Nb}$ contents in phosphorites by X-ray fluorescence. X-Ray Spectrom. 2009, 38, 144-151.

$\mathrm{Da}, \mathrm{X}$.; Chen, X.; Sun, B.; Wen, J.; Qiu, M.; Fan, Y. Preparation of zirconia nanofiltration membranes through an aqueous sol-gel process modified by glycerol for the treatment of wastewater with high salinity. J. Membr. Sci. 2016, 504, 29-39.

Datta, ].; Chowdhury, D. P.; Verma, R. Determination of concentrations of trace elements in nuclear grade graphite by charged particle activation analysis. J Radioanal Nucl Chem. 2014, 300, 147-152.

Dalawat, D. S.; Chauhan, R. S.; Coswami, A. K. Reviews of spectrophotometric methods for determination of zirconium. Rev. Anal. Chem. 2005, $24,75-102$.

Dedkova, V. P.; Shvoeva, O. P.; Savvin, S. B. Sorption-spectrophotometric determination of zirconium and chromium(VI) from a single sample on a two-layer support using arsenazo III and 1,5-diphenylcarbazide. J. Anal. Chem. 2013, 68, 117-122.

Dedkova, V. P.; Shvoeva, O. P.; Savvin, S. B. Sequential determination of nickel(II) and zirconium(IV) with dimethylglyoxime and arsenazo III after adsoprtion on one substrate disc. J. Anal. Chem. 2014, 69, 1037-1040.

Deng, M.; Lin, S.; Bo, X.; Cuo, L. Simultaneous and sensitive electrochemical detection of dihydroxybenzene isomers with UiO- 66 metalorganic framework/mesoporous carbon. Talanta. 2017, 174, 527-538.

Devadas, B.; Rajkumar, M.; Chen, S.-M.; Yeh, P.-C. A novel voltammetric $p$-nitrophenol sensor based on $\mathrm{ZrO}_{2}$ nanoparticles incorporated into a multiwalled carbon nanotube modified glassy carbon electrode. Anal. Methods. 2014, 6, 4686-4691.

Didukh, S. L.; Mukhina, A. N.; Losev, V. N. Sorption-photometric and test-determination of total iron in natural waters using zirconium oxide based sorbents, modified with polyhexamethylene guanidine ferrozine and ferene S. Analytics Control. 2014, 18, 430-437.

Dimitrov, D. T.; Anastasova, S. Y.; Dushkin, C. D. Oxygen sensing junctions based on yttria stabilized zirconia with platinum nanoparticles. Rev. Sci. Instrum. 2006, 77, 056108

Dong, J. X.; Li, N. B.; Luo, H. Q. The formation of zirconium hexacyanoferrate (II) nanoparticles and their application in the highly sensitive determination of dopamine based on enhanced resonance Rayleigh scattering. Anal. Methods. 2013, 5, 5541-5548.

Duodu, G. O.; Coonetilleke, A.; Allen, C.; Ayoko, C. A. Determination of refractive and volatile elements in sediment using laser ablation inductively coupled plasma mass spectrometry. Anal. Chim. Acta. 2015, 898, 19-27.

Fifth Commission Directive 93/73/EEC. In The Rules Coverning Cosmetic Products in the European Union. Vol. 2. Methods of Analysis. Cosmetic Products. European Commission, 1999. p. 129.

Elinson S. V.; Petrov K. I. Analytical chemistry of zirconium and hafnium. Ser. Analytical chemistry of elements; Science: Moscow, 1965, pp. 241.

El-Sayed, A. A.; Hamed, M. M.; El-Reefy, S. A. Determination of micro-amounts of zirconium in mixed aqueous organic mixed aqueous organic medium by normal and first-derivative spectrophotometry. J. Anal. Chem. 2010, 65, 1113-1117.

Emsley ]. The Elements; Clarendon Press: Oxford, 1991; pp 251.

Faghihian, H.; Kabiri-Tadi, M. A novel solid-phase extraction method for separation and preconcentration of zirconium. Microchim. Acta. 2010, 168, 147-152.

Firdaus, M. L.; Norisuye, K.; Sato, T.; Urushihara, S.; Nakagawa, Y.; Umetani, S.; Sohrin, Y. Preconcentration of Zr, Hf, Nb, Ta and W in seawater using solid-phase exctraction on TSK-8-hydroxiquinoline resin and determination by inductively coupled plasma-mass spectrometry. Anal. Chim. Acta. 2007, 583, 296-302.

Fernandez-Ruiz, R.; Andres, R.; de Jesus, E.; Terreros, P. Optimization of the quantitative direct solid total-reflection X-ray fluorescence analysis of glass microspheres functionalized with Zr organometallic compounds. Spectrochim. Acta, Part B.; 2010, 65, 450-456.

Fu, W.; Sun, Y.; Zhang, W. The effect of cooling rate on microstructure and mechanical properties of Zr-based bulk metallic glasses. Adv. Mate. Sci. Eng.; 2013, Article ID 826758.

Garcia, R. H.; Behar, M.; Dias, J. F.; Tagle, M. E.; Rodriguez, M. D.; Pinar, F.; Alfonso, M. S. Determination of Pb, Zr, Ti, Sr, Cr, Nb and La in lead zirconte titanate ceramics by particle-induced X-ray emission. X-Ray Spectrom. 2012, 41, 156-163.

Gautier, C.; Coppo, M.; Caussignac, C.; Laszak, I.; Fichet, P.; Coutelard, F. Zr and U determination at trace level in simulated deep groundwater by Q ICP-MS using extraction chromatography. Talanta. 2013, 106, 1-7.

Chasemi, J. B.; Zolfonoun, E. Simultaneous spectrophotometric determination of trace amounts of uranium, thorium, and zirconium using the partial least squares method after their preconcentration by $\alpha$-benzoin oxime modified Amberlite XAD-2000 resin. Talanta. 2010, $80,1191-1197$

Chasemi, ]. B.; Hashemi, B.; Shamsipur, M. Simultaneous spectrophotometric determination of uranium and zirconium using cloud point extraction and multivariate methods. J. Iran Chem. Soc. 2012, 9, 257-262.

Cholivand, M. B.; Babakhanian, A.; Joshaghani, M. Zirconium ion selective electrode based on bis(diphenylphosphino) ferrocene incorporated in a poly(vinyl chloride) matrix. Anal. Chim. Acta. 2007, 584, 302-307. 
Gidwani, M. S.; Kaur, H.; Pal, U.; Menon, S. K. Chromogenic calixarene hydroxamic acid for the sequentional separation of Ti(IV) and Zr(IV). J. Anal. Chem. 2009, 64, 104-109.

Gleisner, H.; Einax, J. W.; Morés, S.; Welz, B.; Carasek, E. A fast and accurate method for the determination of total and soluble fluorine in toothpaste using high-resolution graphite furnace molecular absorption spectrometry and its comparison with established techniques. J. Pharm. Biomed. Anal. 2011, 54, 1040-1046.

Cong, J.; Miao, X.; Wan, H.; Song, D. Facile synthesis of zirconia nanoparticles-decorated graphene hybrid nanosheets for an enzymeless methyl parathion sensor. Sens. Act. B. 2012, 162, 341-347.

Gregori, G.; Merkle, R.; Maier, J. Ion conduction and redistribution at grain boundaries in oxide systems. Prog. Mater. Sci. 2017, 89, $252-305$.

Gunduz, S.; Akman, S. Determination of bromine by high resolution molecular absorption of strontium mono bromide generated in a graphite furnace. Microchem. J. 2014, 116, 1-6.

Gupta, V. K.; Goyal, R. N.; Sharma, R. A. Novel PVC membrane based alizarin sensor and its application; determination of vanadium, zirconium and molybdenum. Int. J. Electrochem. Sci. 2009, 4, 156-172.

Han, M.-K.; Hwang, M.-J.; Yang, M.-S.; Yang, H.-S.; Song, H.-J.; Park, Y.-J. Effect of zirconium content on the microstructure, physical properties and corrosion behavior of Ti alloys. Mater. Sci. Eng.; A. 2014, 616, 268-274.

Himeno, S.; Kitano, E.; Chaen, N. Simultaneous determination of $\mathrm{Zr}(\mathrm{IV})$ and $\mathrm{Hf}(\mathrm{IV})$ by $\mathrm{CE}$ using precolumn complexation with a $\left[\mathrm{PW}_{11} \mathrm{O}_{39}\right]^{7-}$ ligand. Electrophoresis. 2007, 28, 1525-1529.

Huang, M. D.; Becker-Ross, H.; Okruss, M.; Geisler, S.; Florek, S.; Richter, S.; Meckelburg, A. Direct determination of fluorine in niobium oxide using slurry sampling electrothermal high-resolution continuum source molecular absorption spectrometry. Spectrochim. Acta, Part B. 2014, 94-95, 34-38.

Ichikawa, S.; Matsumoto, T.; Nakamura, T. X-ray fluorescence determination using glass bead samples and synthetic calibration standards for reliable routine analyses of ancient pottery. Anal. Methods. 2016, 8, 4452-4465.

ISO 21079-2:2008. Chemical analysis of refractories containing alumina, zirconia, and silica - refractories containing 5 percent to 45 percent of $\mathrm{ZrO}_{2}$ (alternative to the X-ray fluorescence method). Part 2: Wet chemical analysis. 2008, pp. 18.

ISO/TS 16965:2013. Soil quality - determination of trace elements using inductively coupled plasma mass spectrometry (ICP-MS). $2013 ;$ pp 13.

Jayalatha, T.; Sivadas, D. L.; Dimple, R.; Jacob, S.; Rajeev, R.; Rao, V. L. Analysis of trace additives in copper alloys for space applications: a comparison between graphite furnace atomic absorption spectrometry and inductively coupled plasma atomic emission spectrometry. Mater. Sci. Forum. 2012, 710, 588-593.

Kahkla, M. R. R.; Daliran, S.; Oveisi, A. R.; Kaykhaii, M.; Sepehri, Z. The mesoporous porphyrinic zirconium metal-organic framework for pipette-tip solid-phase extraction of mercury from fish samples followed by cold vapor atomic absorption spectrometric determination. Food Anal. Methods. 2017, 10, 2175-2184.

Karami, H.; Mousavi, M. F.; Yamini, Ya.; Shamsipur, M. On-line solid phase extraction and simultaneous determination of hafnium and zirconium by ICP-atomic emission spectroscopy. Microchim. Acta. 2006, 154, 221-228.

Karve, M.; Cholave, J. V. Amberlite XAD-2 impregnated with Cyanex 272 for zirconium(IV) enrichment followed by spectrophotometric determination. Desalin. Water Treat. 2014, 52, 452-458.

Katunar, M. R.; Sanchez, A. G.; Coquillat, A. S.; Civantos, A.; Campos, E. M.; Ballarre, J.; Vico, T.; Baca, M.; Ramos, V.; Cere, S. In vitro and in vivo characterization of anodised zirconium as a potential material for biomedical applications. Mater. Sci. Eng.; C. 2017, 75, 957-968.

Kaczynski, P.; Hrynko, I.; Lozowicka, B. Evolution of novel sorbents for effective clean-up of honeybee matrix in highly toxic insecticide LC/MS/MS analysis. Ecotoxicol. Environ. Saf. 2017, 139, 124-131.

Keitl, G.; Rink, J.; Wen, F.; Jongen, L.; Hofmann, A.; Votsmeier, M.; Terfort, A.; Gieshoff, J. Impact of test conditions on the oxygen storage capacity of Pd loaded cerium zirconium oxide. Top. Catal. 2017, 60, 272-277.

Klumov, B. A.; Ryltsev, R. E.; Chtchelkatchev, N. M. Simulated Cu-Zr glassy alloys: the impact of composition on icosahedral order. JEPT Letters. 2016, 104, 556-561.

Kon, Y.; Murakami, H.; Takagi, T.; Watanabe, Y. The development of whole rock analysis of major and trace elements in XRF glass by fsLAICPMS in CS] geochemical reference samples. Geochem. J. 2011, 45, 387-416.

Krishna, K.; Khanna, T. C.; Mohan, K. R. Rapid quantitative determination of major and trace elements in silicate rocks and soils employing fused glass discs using wavelength dispersive X-ray fluorescence spectrometry. Spectrochimica Acta, Part B. 2016, 122, $165-171$.

Kulikova, T. V.; Majorova, A. V.; Shunyaev, K.Yu.; Ryltsev, R. E. Thermodynamic properties of Cu-Zr melts: The role of chemical interaction. Physica B. 2015, 466-467, 90-95.

Kumar, A. P.; Muthaiah, V. M. S.; Mula, S. Effect of Nb, Y and Zr on thermal stability of nanocrystalline Al-4.5 wt.\% Cu alloy prepared by mechanical alloying. J. Alloys Compd. 2017, 722, 617-627.

Lee, D. B. N.; Roberts, M.; Bluchel, C. G.; Odell, R. A. Zirconium: biomedical and nephrological applications. ASAIO Journal. 2010, 56, 550-556.

Lee, C. B.; Cheon, J. S.; Kim, S. H.; Park, J.-Y.; Joo, H.-K. Joo fuel development and verification for prototype generation IV sodium-cooled fast reactor. Nucl. Eng. Technol 2016, 48, 1096-1108.

Levytska, H.; Bilyk, O.; Dubenska, L. Voltammetric determination of Zr(IV) based on complexation reaction with azodyes. Chem. Anal. (Warsaw). 2006, 51, 391-397.

Li, Y.-H.; Zhao, Q.-L.; Huang, M.-H. Adsorptive anodic stripping voltammetry of zirconium(IV)-alizarin red S complex at a carbon paste electrode. Microchim. Acta. 2007, 157, 245-249.

Li, N.-N.; Kang, T.-F.; Zhang, J.-J.; Lu, L.-P.; Cheng, S.-Y. Fe $\mathrm{O}_{4} @ \mathrm{ZrO}_{2}$ magnetic nanoparticles as a new electrode material for sensitive determination of organophosphorus agents. Anal. Methods. 2015, 7, 5053-5059.

Li, J.; Liu, Y.; Su, H.; Wong, Y.-L. E.; Chen, X.; Chan, T.-W. D.; Chen, Q. In situ hydrothermal growth of a zirconium-based porphyrinic metalorganic framework on stainless steel fibers for solid-phase microextraction of nitrated polycyclic aromatic hydrocarbons. Microchim. Acta. 2017, 184, 3809-3815.

Liu, Y.; Zhou, S.; Tu, D.; Chen, Z.; Huang, M.; Zhu, H.; Ma, E.; Chen, X. Amine-functionalized lanthanide-doped zirconia nanoparticles: optical spectroscopy, time-resolved fluorescence resonance energy transfer biodetection, and targeted imaging. J. Am. Chem. Soc. 2012, 134, 15083-15090. 
Lonkar, C. M.; Kharat, D. K.; Kumar, H. H.; Prasad, S.; Chosh, M.; Kumbhar, C. S. Effect of Zr/Ti ratio on piezoelectric properties of $\mathrm{Pb}\left(\mathrm{Ni}_{1 / 3} \mathrm{Sb}_{2 / 3}\right) \mathrm{O}_{3}-\mathrm{Pb}(\mathrm{ZrTi}) \mathrm{O}_{3}$ ceramics. Thin Solid Films. 2011, 37, 3509-3514.

Lopez, T. M.; Avnir, D.; Aegerter, M. A., Ed. Emerging Fields in Sol-Cel Science and Technology; Springer: Boston, USA, 2003; pp 454.

Louzgine-Luzgin, D. V.; Inoue, A. Chapter three - Bulk metallic glasses. Formation, structure, properties and applications. Handbook Magn. Mater. 2013, 21, 131-172.

Lu, Y.; Chen, T.; Chen, X.; Qiu, M.; Fan, Y. Fabrication of $\mathrm{TiO}_{2}$-doped $\mathrm{ZrO}_{2}$ nanofiltration membranes by using a modified colloidal sol-gel process and its application in simulative radioactive effluent. J. Membr. Sci. 2016, 514, 476-486.

Macarovscha, G. T.; Bortoleto, G. G.; Cadore, S. Silica modified with zirconium oxide for on-line determination of inorganic arsenic using a hydride generation-atomic absorption system. Talanta. 2007, 71, 1150-1154.

Meeravali, N. N.; Reddy, M. A.; Kumar, S. J. Studies on reduction of chloride matrix interferences on determination of germanium using zirconium-ruthenium and palladium-magnesium modifiers by electrothermal atomic absorption spectrometry. Spectrochim. Acta, Part B. $2007,62,504-508$.

Meng, Z.; Zheng, J.; Li, Q. A nitrite electrochemical sensor based on electrodeposition of zirconium dioxide nanoparticles on carbon nanotubes modified electrode. J. Iran. Chem. Soc. 2015, 12, 1053-1060.

Mittal, S. K.; Kumar, R.; Dogra, P.; Sharma, H. K. Potentiometric determination of disprosium(III) ion using zirconium(IV) antimonomolibdate as electroactive material. J. Anal. Chem. 2010, 65, 1045-1051.

Mketo, N.; Nomngongo, P. N.; Ngila, ]. C. A rapid microwave-assisted acid extraction method based on the use of diluted $\mathrm{HNO}_{3}-\mathrm{H}_{2} \mathrm{O}_{2}$ followed by ICP-MS analysis for simultaneous determination of trace elements in coal samples. Intern. J. Environ. Anal. Chem. 2015, 95, 453465 .

Mohammadizadeh, N.; Mohammadi, S. Z.; Kaykhaii, M. Highly sensitive amperometric detection of propranolol using graphite screen printed electrode modified with zirconium dioxide nanoparticles. Anal. Bioanal. Electrochem. 2017, 9, 277-285.

Molnar, A. Catalytic applications of amorphous alloys: expectations, achievements, and disappointments. Appl. Surf. Sci. 2011, 257, 8151-8164.

Monji, A. B.; Zolfonoun, E.; Ahmadi, S. J. Application of acidic extract of Platanus orientalis tree leaves as a green reagent for selective spectrophotometric determination of zirconium. Green Chem. Lett. Rev. 2008, 1, 107-112.

Mortada, W. I.; Ali, A. Z.; Hassanien, M. M. Mixed micelle-mediated extraction of alizarin red S complexes of Zr(IV) and Hf(IV) ions prior to their determination by inductively coupled plasma-optical emission spectrometry. Anal. Metods. 2013, 5, 5234-5240.

Mukherji, A. K. Analytical Chemistry of Zirconium and Hafnium. International Series of Monographs in Analytical Chemistry, Vol. 40.; Pergamon press: Oxford, 1970; pp 280.

Nagaishi, K.; Ishikawa, T. A simple method for the precise determination of boron, zirconium, niobium, hafnium and tantalum using ICP-MS and new results for rock reference samples. Geochem. J. 2009, 43, 133-141.

Nagy, L. N.; Mihaly, J.; Polyak, A.; Debreczeni, B.; Csaszar, B.; Szigyarto, I. C.; Wacha, A.; Czegeny, Z.; Jakab, E. Inherently fluorescent and porous zirconia colloids: preparation, characterization and drug adsorption studies. J. Mater. Chem. B. 2015, 3, 7529-7537.

Nagy, L. N.; Polyak, A.; Mihály, J.; Szécsényi, Á.; Szigyártó, I. C.; Czégény, Z.; Jakab, E.; Németh, P.; Magda, B.; Szabó, P.; Veres, Z.; Jemnitz, K.; Bertóti, I.; Jóba, R. P.; Trencsényi, G.; Balogh, L.; Bóta, A. Silica@zirconia@poly(malic acid)nanoparticles: promising nanocarriers for theranostic applications. J. Mater. Chem. B, 2016, 4, 4420-4429.

Nebel, O.; Marel, M. L. A.; Vroon, P. Z. Isotope dilution determinations of Lu, Hf, Zr, Ta and W, and Hf isotope compositions of NIST SRM 610 and 612 glass wafers. Ceostand. Ceoanal. Res. 2009, 33, 487-499.

Nemeryuk, A. M.; Lylina, M. M. Structure and tribological properties of self-reinforced composite materials based on UHMWPE and oxides of titanium, zirconium and hafnium. Orient. J. Chem. 2017, 33, 995-1000.

Osváth, Sz.; Vajda, N.; Stefánka, Zs.; Széles, E.; Molnár, Zs. Determination of ${ }^{93} \mathrm{Zr}$ and ${ }^{237} \mathrm{~Np}$ in nuclear power plant wastes. J. Radioanal. Chem. 2011, 287, 459-463.

Otto, M.; Wegscheider, W. Limitations of spectrophotometric multicomponent analysis of metal ions with mixed reagents. Anal. Chem. 1989, $61,1847-1851$.

Park, C.-S.; Shin, H. S.; Oh, H.; Moon, J. H.; Cho, H.; Cheong, C. Determination of trace elements in geological reference materials G-3, CSP-2 and SCD-1 a by low-dilution glass bead digestion and ICP-MS. Ceostand. Ceoanal. Res. 2012, 37, 361-368.

Pasias, I. N.; Thomaidis, N. S.; Bakeas, E. B.; Piperaki, E. A. Application of zirconium-iridium permanent modifier for the simultaneous determination of lead, cadmium, arsenic and nickel in atmospheric particulate matter by multi-element electrothermal atomic absorption spectrometry. Environ. Monit. Assess. 2013, 185, 6867-6879.

Pecev, T. G.; Deki, S. V.; Petkovi, B. B.; Simonov, R. M.; Noro, D. M. A new kinetic method for photometric determination of trace $\mathrm{Zr}(\mathrm{IV})$ in industrial Al-Li alloys. Chem. Anal. (Warsaw). 2007, 52, 511-520.

Pechishcheva, N. V.; Evdokimova, O. V.; Mayorova, A. V.; Shunyaev, K. Yu. Determination of the main components of amorphized CuZr alloys. Inorg. Mater. 2017, 53, 1405-1410.

Pereira, E. R.; Castilho, I. N. B.; Welz, B.; Gois, J. S.; Borges, D. L. G.; Carasek, E.; Andrade, J. B.de. Method development for the determination of bromine in coal using high-resolution continuum source graphite furnace molecular absorption spectrometry and direct solid sample analysis. Spectrochim. Acta, Part B. 2014, 96, 33-39.

Pereira, E. R.; Merib, J.; Cadorim, H. R.; Schneider, M.; Carvalho, C. S.; Duarte, F. A.; Welz, B.; del Campo Menoyo, J.; Feldmann, J. Development of a fast screening method for the direct determination of chlorinated persistent organic pollutants in fish oil by high-resolution continuum source graphite furnace molecular absorption spectrometry. Food Control. 2017, 78, 456-462.

Petrelli, M.; Perugini, D.; Poli, G.; Peccerillo, A. Graphite electrode lithium tetraborate fusion for trace element determination in bulk geological samples by laser ablation ICP-MS. Microchim Acta. 2007, 158, 275-282.

Petrov, P. K.; Serafimovski, I.; Stafilov, T.; Tsalev, D. L. Flow injection hydride generation electrothermal atomic absorption spectrometric determination of toxicologically relevant arsenic in urine. Talanta. 2006, 69, 1112-1117.

Plashnitsa, V. V.; Elumalai, P.; Miuraa, N. Sensitive and selective zirconia-based $\mathrm{NO}_{2}$ sensor using gold nanoparticle coatings as sensing electrodes. J. Electrochem. Soc. 2008, 155, J301-J306. 
Poehle, S.; Schmidt, K.; Koschinsky, A. Koschinsky of Ti, Zr, Nb, V, W and Mo in seawater by a new online-preconcentration method and subsequent ICP-MS analysis. Deep Sea Res. Part I 2015, 98, 83-93.

Pourreza, N.; Parham, H.; Shiri, S. Determination of trace amounts of zirconium by flotation - spectrophotometric method. J. Korean Chem. Soc. 2010, 54, 283-286.

Pourreza, N.; Mouradzadegun, A.; Mohammadi, S. Solid phase extraction of zirconium as arsenazo(II) complex on agar and spectrophotometric determination. J. Iran. Chem. Soc. 2011, 8, 951-957.

Pupyshev A. A. Atomic Absorption Spectral Analysis; Technosphere: Moscow, 2009; pp 784.

Qiao, J.; Pelletier, ].; Casalini, R. Relaxation of bulk metallic glasses studied by mechanical spectroscopy. J. Phys. Chem. B. 2013, 117, 1365813666.

Quemet, A.; Maillard, C.; Ruas, A. Determination of zirconium isotope composition and concentration for nuclear sample analysis using thermal ionization mass-spectrometry. Int. J. Mass. Spectrom. 2015, 392, 34-40.

Raso, M.; Censi, P.; Saiano, F. Simultaneous determinations of zirconium, hafnium, yttrium and lanthanides in seawater according to a coprecipitation technique onto iron-hydroxide. Talanta. 2013, 116, 1085-1090.

Rejczak, T.; Tuzimski, T. Method development for sulfonylurea herbicides analysis in rapeseed oil samples by HPLC-DAD: Comparison of zirconium-based sorbents and EMR-lipid for clean-up of QuEChERS extract. Food Anal. Methods. 2017a, 10, 3666-3679.

Rejczak, T.; Tuzimski, T. QuEChERS-based extraction with dispersive solid phase extraction clean-up using PSA and $\mathrm{ZrO}_{2}$-based sorbents for determination of pesticides in bovine milk samples by HPLC-DAD. Food Chem. 2017b, 217, 225-233.

Rietig, A.; Acker, J. Development and validation of a new method for the precise and accurate determination of trace elements in silicon by ICP-OES in high silicon matrices. J. Anal. At. Spectrom. 2017, 32, 322-333.

Romanova, N. B.; Pechishcheva, N. V.; Shunyaev, K.Yu.; Titov, V. I.; Gundobin, N. V. Determining low concentration of Zr, Ce, La, and Y in heatresistant nickel alloys by inductively coupled plasma atomic emission. Inorg. Mater. 2012, 48, 1315-1319.

Savchenko, A. M.; Vatulin, A. V.; Morozov, A. V.; Kulakov, G. V.; Ershov, S. A.; Laushkin, A. V.; Maranchak, S. V.; Konovalov, Y. V.; Malamanova, E. K. Zirconium alloys matrix as innovative material for composite fuel. Prog. Nucl. Energy. 2012, 57, 138-144.

Samuel, A. M.; Alkahtani, S. A.; Doty, H. W.; Samuel, F. H. Role of Zr and Sc addition in controlling the microstructure and tensile properties of aluminum-copper based alloys. Mater. Des. 2015, 88, 1134-1144.

Sedykh, E. M.; Starshinova, N. P.; Medvedeva, L. S. Determination of titanium, zirconium and silicon by AES-ISP in experimental geochemical solutions. Factory laboratory. Diagnosis of materials (Zavodskaya laboratoriya. Diagnostika materialov). 2013, 79, $19-22$.

Schenk, E. R.; Almirall, J. R. Elemental analysis of glass by laser ablation inductively coupled plasma optical mission spectrometry (LA-ICPOES). Forensic Sci. Int. 2012, 217, 222-228.

Schneider, A. B.; Nascimento, P. C.; Bohrer, D.; de Carvalho, L. M.; Guarda, A.; Krause, C.; Wiethan, B. A.; Koschinsky, A. Determination of zirconium and vanadium in natural waters by adsorptive stripping voltammetry in the presence of cupferron, oxalic acid and 1,3diphenylguanidine. Electroanalysis. 2015, 27, 1864-1870.

Sequeira, S.; Fernandes, M. H.; Neves, N.; Almeida, M. M. Development and characterization of zirconia-alumina composites for orthopedic implants Ceram. Int. 2017, 43, 693-703.

Shackelford, J.; Doremus R. H. Ceramic and Class Materials. Structure, Properties and Processing; Springer: US, 2008; pp 202.

Shahid, M.; Ferrand, E.; Schreck, E.; Dumat, C. Behavior and impact of zirconium in the soil-plant system: plant uptake and phytotoxicity. Rev. Environ. Contam. Toxicol. 2013, 221, 107-127.

Shams, E.; Babaei, A.; Taheri, A. R.; Kooshki, M. Voltammetric determination of dopamine at a zirconium phosphated silica gel modified carbon paste electrode. Bioelectrochem. 2009, 75, 83-88.

Shams, E.; Torabi, R. Determination of nanomolar concentrations of cadmium by anodic-stripping voltammetry at a carbon paste electrode modified with zirconium phosphated amorphous silica. Sens. Actuators, B. 2006, 117, 86-92.

Shariati, S.; Yamini, Y.; Zanjani, M. K. Simultaneous preconcentration and determination of U(VI), $\operatorname{Th}(\mathrm{IV}), \mathrm{Zr}(\mathrm{IV})$ and Hf(IV) ions in aqueous samples using micelle-mediated extraction coupled to inductively coupled plasma-optical emission spectrometry. J. Hazard. Mater. 2008, 156, 583-590.

Shen, J.; Nardello-Rataj, V. Antitranspirants et déodorants: de la chimie sous les bras. L'actualite chimique. 2009, 331, 8-18.

Shervedani, R. K.; Pourbeyram, S. Zirconium immobilized on gold-mercaptopropionic acid self-assembled monolayer for trace determination of phosphate in blood serum by using CV, EIS, and OSWV. Biosens. Bioelectron. 2009, 24, 2199-2204.

Shervedani, R. K.; Bagherzadeh, M. Electrochemical impedance spectroscopy as a transduction method for electrochemical recognition of zirconium on gold electrode modified with hydroxamated self-assembled monolayer. Sens. Actuators, B. 2009, 139, 657-664.

Shokrollahi, A.; Cohari, M. Flame atomic absorption determination of zirconium in glass and refractory bricks after coprecipitation with aluminium hydroxide. J. Taibah Univ. Sci. 2017, 11, 540-547.

Shvoeva, O. P.; Dedkova, V. P.; Savvin, S. B. Sorption-spectroscopy determination of zirconium on a PANV-KU-2 fibrous ion exchanger using Arsenazo III. J. Anal. Chem. 2012, 67, 515-518.

Sorescu, M.; Diamandescu, L.; Tomescu, A.; Krupa, S. Synthesis and sensing properties of zirconium-doped hematite nanoparticles. Physica B. 2009, 404, 2159-2165.

Su, X. F.; Zhou, Q. X.; Zhao, X. N.; Xie, G. H. Fluorometric determination of nonylphenol in water samples enriched with zirconium doped titanium dioxide nanotubes solid phase extraction. Chin. Chem. Lett. 2012, 23, 969-972.

Sun, S.; Li, J. Determination of Zr, Nb, Mo, Sn, Hf, Ta, and W in seawater by $\mathrm{N}$-benzoyl-N-phenylhydroxylamine extraction chromatographic resin and inductively coupled plasma-mass spectrometry. Microchem. J. 2015, 119, 102-107.

Swaine, D. J. Trace Elements in Coal; Butterworth and Co. (Publishers) Ltd.: London, 1990; pp 278.

Tindemans, T.; Dobney, A.; Wambeke, D.; Vanhaecke, F. Development and application of an analyte/matrix separation procedure for multielement trace analysis of steel alloys by means of sector-field ICP-mass spectrometry. J. Anal. At. Spectrom. 2014, 29, 1073-1081.

Uysal, U. D.; Huseyinli, A. A.; Cüray, T. Rapid direct spectrophotometric determination of zirconium(IV) in alloys with 2,2',3,4-tetrahydroxy-3'sulpho-5'-carboxyazobenzene reagent. J. Sci. Ind. Res. 2011, 70, 45-50. 
Varghese, A.; Ceorge, L. Simultaneous first order derivative spectrophotometric determination of vanadium and zirconium in alloy steels and minerals. Spectrochim. Acta, Part A. 2012, 95, 46-52.

Vining, W. C.; Strunk, J.; Bell, A. T. Investigation of the structure and activity of $\mathrm{VO}_{x} / \mathrm{ZrO}_{2} / \mathrm{SiO}_{2}$ catalysts for methanol oxidation to formaldehyde. J. Catal. 2011, 281, 222-230.

Viswanathan, S.; Suria, K.; Rao, P.; Mahabaleswar, B. Wavelength-dispersive X-ray fluorescence spectrometric determination of Sc, V, Cr, Co, $\mathrm{Ni}, \mathrm{Cu}, \mathrm{Zn}, \mathrm{Rb}, \mathrm{Sr}, \mathrm{Y}, \mathrm{Zr}, \mathrm{Nb}, \mathrm{Ba}, \mathrm{Pb}$, and Th in Komatiites. J. Ceol. Soc. India. 2013, 82, 621-627.

Volynsky, A. B. Application of graphite tubes modified with high-melting carbides in electrothermal atomic absorption spectrometry. I. Ceneral approach. Spectrochim. Acta, Part B. 1998, 53, 509-535.

Wold, S.; Antti, H.; Lindgren, F.; Ohman, J. Orthogonal signal correction of near-infrared spectra. Chemometr. Int. Lab. Syst. 1998, 44, 175-185.

Xi, T. H.; Li, P. H.; Yuan, Z. X. Effects of zirconium on microsructure and mechanical properties of microalloyed steels. Acta Metall. Sinica (Eng. Lett.). 2006, 19, 319-327.

Xia, L.; Liu, L.; Xu, X.; Zhu, F.; Wang, X.; Zhang, K.; Yang, X.; You, J. Determination of chlorophenoxy acids herbicides by using zirconium based metal-organic framework as special sorbent for dispersive micro-solid-phase extraction and high performance liquid chromatography. New J. Chem. 2017, 41, 2241-2248.

Xin, Y.; Sun, L.-X.; Yang, Z.-J.; Zeng, P.; Cong, Z.-B.; Qi, L.-F. In situ analysis of magnesium alloy using a standoff and double-pulse laserinduced breakdown spectroscopy system. Front. Phys. 2016, 11, 115207-1-115207-10.

Yadav, A.; Bhowmik, D.; Sikder, N. Direct determination of zirconium and silicon in zircon by flame atomic absorption spectrometry using two rapid decomposition methods. Anal. Methods. 2012, 4, 2454-2461.

Yang, B.; Fan, Z. Speciation analysis of chromium in natural water samples by electrothermal atomic absorbance spectrometry after separation/preconcentration with nanometer zirconium phosphate. J. Anal. Chem. 2012, 67, 443-447.

Yang, J.; Zheng, M.; Liu, Q.; Zhu, M.; Yang, C.; Zhang, Y.; Zhu, Z. The Study of titanium and zirconium ions in water by MPT-LTQ mass spectrometry in negative mode. Int. J. Environ. Res. Public Health. 2017, 14, 1129.

Yasin, A. S.; Obaid, M.; El-Newehy, M. H.; Al-Deyab, S. S.; Barakat, N. A. M. Influence of $\mathrm{Ti}_{x} \mathrm{Zr}_{(1-x)} \mathrm{O}_{2}$ nanofibers composition on the photocatalytic activity toward organic pollutants degradation and water splitting. Ceram. Int. 2015, 41, Part B, 11876-11885.

Yildiz, Y. Gravimetric determination of percentage zirconium in cement based ultra Temp-516 using mandelic acid. J. Sci. Eng. Res. 2017, 4, 94-96.

Yu, C.; Liu, G.; Zuo, B.; Tang, R. A novel gaseous dimethylamine sensor utilizing cataluminescence on zirconia nanoparticles. Luminescence. 2009, 24, 282-289.

Yurchenko, N. Y.; Stepanov, N. D.; Zherebtsov, S. V.; Tikhonovsky, M. A.; Salishchev, G. A. Structure and mechanical properties of B2 ordered refractory AlNbTiVZr $r_{x}(x=0-1.5)$ high-entropy alloys. Mater. Sci. Eng. A. 2017, 704, 82-90.

Zavodinsky, V. G.; Chibisov, A. N. Stability of cubic zirconia and of stoichometric zirconia nanoparticles. Phys. Solid State. 2006, 48, 363-368.

Zhai, Q. Z. Determination of trace amount of oxalic acid with zirconium(IV)-(DBS-arsenazo) by spectrophotometry. Spectrochim. Acta, Part A. 2008, 71, 332-335.

Zhang, Z. H.; Li, T. S. Applications of zirconium (IV) compounds in organic synthesis. Curr. Org. Chem. 2009, 13, 1-30.

Zhang, X. X.; Zhao, Y.; Wang, S. M.; Zhai, Q. Z. Spectrophotometric determination of zirconium in water samples. Asian J. Chem. 2013, 25, 587588.

Zhang, W.; Qi, L.; Hu, Z.; Zheng, C.; Liu, Y.; Chen, H.; Gao, S.; Hu, S. An investigation of digestion methods for trace elements in bauxite and their determination in ten bauxite reference materials using inductively coupled plasma-mass spectrometry. Geostand. Geoanal. Res. 2015, 40, 195-216.

Zhang, H.; Zhu, H.; Nie, X.; Yin, J.; Hu, Z.; Zeng, X. Effect of zirconium addition on crack, microstructure and mechanical behavior of selective laser melted Al-Cu-Mg alloy. Scr. Mater. 2017a, 134, 6-10.

Zhang, Z.-H.; Duan, F.-H.; Tian, J.-Y.; He, J.-Y.; Yang, L.-Y.; Zhao, H.; Zhang, S.; Liu, C.-S.; He, L.-H.; Chen, M.; Chen, D.-M.; Du, M. Aptamerembedded zirconium-based metal-organic framework composites prepared by de novo bio-inspired approach with enhanced biosensing for detecting trace analytes. ACS Sens. 2017b, 2, 982-989.

Zhao, S.; Wang, H.; Xiao, L.; Guo, N.; Zhao, D.; Yao, K.; Chen, N. High strain rate sensitivity of hardness in quinary Ti-Zr-Hf-Cu-Ni high entropy metallic glass thin films. Physica E. 2017, 94,100-105.

Zheng, F.-Y.; Li, S.-X.; Lin, L.-X.; Cheng, L.-Q. Simple and rapid spectrophotometric determination of trace titanium (IV) enriched by nanometer size zirconium dioxide in natural water. J. Hazard. Mater. 2009, 172, 618-622.

Zyryanov, V. V.; Uvarov, N. F.; Ulikhin, A. S.; Kostrovskii, V. G.; Bokhonov, B. B.; Ivanov, V. P.; Sadykov, V. A.; Titov, A. T.; Paichadze, K. S. Conductivity of the nanostructured ceramic material $\mathrm{Zr}_{0.88} \mathrm{Sc}_{0.1} \mathrm{Ce}_{0.01} \mathrm{Y}_{0.01} \mathrm{O}_{1.955}$ prepared from mechanically activated powders. Inorg. Mater. 2009, 45, 90-98. 